\title{
Injectable Enzymatically Hardened Calcium Phosphate Biocement
}

\author{
Lubomir Medvecky ${ }^{1, *(\mathbb{C}, \text { Radoslava Štulajterová }}{ }^{1}$, Maria Giretova ${ }^{1}$, Lenka Luptakova ${ }^{2}(\mathbb{D}$ and \\ Tibor Sopčák ${ }^{1}$ (D) \\ 1 Institute of Materials Research of SAS, Watsonova 47, 04001 Kosice, Slovakia; rstulajterova@saske.sk (R.Š.); \\ mgiretova@saske.sk (M.G.); tsopcak@saske.sk (T.S.) \\ 2 Institute of Biology, Zoology and Radiology, University of Veterinary Medicine and Pharmacy in Kosice, \\ Komenskeho 73, 04181 Kosice, Slovakia; lenka.luptakova@uvlf.sk \\ * Correspondence: lmedvecky@saske.sk
}

Received: 7 August 2020; Accepted: 2 October 2020; Published: 12 October 2020

\begin{abstract}
Background: The preparation and characterization of novel fully injectable enzymatically hardened tetracalcium phosphate/monetite cements (CXI cements) using phytic acid/phytase (PHYT/F3P) hardening liquid with a small addition of polyacrylic acid/carboxymethyl cellulose anionic polyelectrolyte (PAA/CMC) and enhanced bioactivity. (2) Methods: Composite cements were prepared by mixing of calcium phosphate powder mixture with hardening liquid containing anionic polyelectrolyte. Phase and microstructural analysis, compressive strength, release of ions and in vitro testing were used for the evaluation of cement properties. (3) Results: The simple possibility to control the setting time of self-setting CXI cements was shown (7-28 $\mathrm{min}$ ) by the change in $\mathrm{P} / \mathrm{L}$ ratio or PHYT/F3P reaction time. The wet compressive strength of cements (up to $15 \mathrm{MPa}$ ) was close to cancellous bone. The increase in PAA content to $1 \mathrm{wt} \%$ caused refinement and change in the morphology of hydroxyapatite particles. Cement pastes had a high resistance to wash-out in a short time after cement mixing. The noncytotoxic character of CX cement extracts was verified. Moreover, PHYT supported the formation of Ca deposits, and the additional synergistic effect of PAA and CMC on enhanced ALP activity was found, along with the strong up-regulation of osteogenic gene expressions for osteopontin, osteocalcin and IGF1 growth factor evaluated by the RT-qPCR analysis in osteogenic $\alpha$ MEM 50\% CXI extracts. (4) Conclusions: The fully injectable composite calcium phosphate bicements with anionic polyelectrolyte addition showed good mechanical and physico-chemical properties and enhanced osteogenic bioactivity which is a promising assumption for their application in bone defect regeneration.
\end{abstract}

Keywords: calcium phosphate cement; phytic acid; polyacrylic acid; setting process; in vitro

\section{Introduction}

Calcium phosphate biocements (CPC) represent biomaterials which are continuously improved in terms of their positive biological properties like biocompatibility, osteoinductivity, osteoconductivity as well as other physico-chemical or mechanical properties. CPCs are characterized by specific properties, which predetermine their perfect filling to various types of bone defects in the maxillofacial, cranial area [1,2], dentistry and orthopedics [3]. For the above applications, a considerable degree of plasticity especially in the stage of cement paste is a very important characteristic. The final products of CPC hardening are the specific forms of nanocrystalline or amorphous calcium deficient hydroxyapatite (HAP), which support the activity of specific bone cells (osteoclasts, osteoblasts) and promote the cell proliferation and growth not only due to a rise in the concentration of calcium and phosphate ions around the implanted biocement, but also the presence of a large proportion of micropores in the 
microstructure with corresponding large specific surface area. The appropriate microstructure provides suitable conditions for the adsorption of various types of cytokines, proteins (e.g., morphogenic proteins, extracellular adherins) stimulating the biological activity of cells. The applicability of CPC in the bone defect treatment in practice can be significantly improved if cement pastes are injectable and strongly adherent to the surrounding tissue. In practice, three types of injectable cements are used, based on methacrylate composites (presence of free monomer, low bioactivity, non-resorbable, high temperature during polymerization), calcium sulfate cements (rapidly resorbable and increased solubility in body fluids) and calcium phosphate cements (problems with $\mathrm{pH}$, longer setting time, problematic viscoelastic properties) [4]. The highest biocompatibility (not only from the aspect of low irritation of the surrounding tissues, but also chemical, phase and structural compatibility, low cytotoxicity) was achieved in the case of CPC. Previously used injectable CPC pastes were not only composed of the standard calcium phosphates such as tetracalcium phosphate, tricalcium phosphate, brushite with additions of HAP and calcium carbonate but also contained phosphate solution which can contain polymerizable components, e.g., bisGMA resp. methacrylate. The effect of chitosan, starch, gelatin or silanization as well as the addition of bioactive glasses on the mechanical properties, biodegradability and proliferation of osteoblasts on cement composites has been studied [5]. These systems were composed of calcium phosphates and a liquid phase ensuring sufficient viscosity, which, in addition, can react with the cement mixture or serve to polymerize with the aim to strengthen the overall composite system. Another possible solution is represented by the formation of composite hydrogel systems in combination with solid powdered cement mixtures of calcium phosphates, which affects their mechanical, physico-chemical and biological properties [6-9] Hydrogels in the systems mimic both the extracellular matrix and biomimetic structure of hard tissues, which consequently support the adsorption of specific growth factors, adherins as well as the interaction of the cells themselves [10]. On the other hand, the mechanical properties are generally significantly reduced but are suitable for the reconstruction of defects especially in the trabecular bone. From the point of view of the applicability of cements, an extreme increase in their setting time is not acceptable either. In the case of hybrid composites, the direct precipitation of calcium phosphates into neutral hydrogels, e.g., polyvinyl alcohol, hydroxymethyl cellulose [6,11] was applied and the stronger mutual interactions were observed using polyelectrolytes such as chitosan and gelatin $[12,13]$. To form specific calcium phosphate structures, hydrogels from collagen, silk, various peptides, soluble forms of cellulose, poly-lactic acid. chitosan or solid polymeric substrates have been extensively studied [14,15]. The mutual interactions between biopolymer polyelectrolytes with the formation of complexes $[15,16]$ as well as their ability to form complexes with divalent and trivalent metal ions [17] are important for the strengthening of the microstructure of composites. The calcium phosphate-loaded carboxymethyl cellulose (CMC) nonwoven sheets showed a significantly higher new bone formation rate in the composites than that in the CMC group [18]. The CPC/poly(lactic-co-glycolic acid/CMC composite showed a good long-term biological response and the new bone formation in vivo [19]. The TTCP/DCPA/CMC cement had adequate osteoconductivity, biocompatibility and adequate compressive strength in an in vivo sheep vertebral bone void model [20]. The calcium phosphate composite cements with polyacrylic acid (PAA) demonstrated adjustable brittle/ductile strength at high PAA contents (up to $50 \mathrm{wt} \%$ ) after setting [21].

The phytic acid (PHYT) had positive effects on depressing the stone formation, stem calcification, reducing the progression of osteoporosis and, e.g., an anticancer effect [22-24]. The PHYT can reduce the $\mathrm{pH}$ in the body defect site with a possible positive effect on the activity of osteoclasts (at weak acid or neutral $\mathrm{pH}$ (6.5-7) conditions) [25]. The formation of $\mathrm{Ca}^{2+}-\mathrm{PHYT}$ complexes is responsible for the decrease in the crystallization rate of hydroxyapatite [26]. Retarding properties of PHYT were demonstrated in the case of setting Mg-type cement with newberyite and farringtonite as final products [27]. In previous work, we studied the possibility of the preparation of TTCP/DCPA fast-setting cement with hardening liquid containing PHYT and the influence of PHYT on cement properties [28]. 
The above facts clearly indicate the relevance to focus on the preparation and development of new types of hybrid biocement self-setting systems with in situ precipitated calcium phosphate nanoparticles in biopolymer polyelectrolyte, which have been studied relatively little in this connection. In this paper, we focused on the preparation of hybrid injectable self-setting TTCP/DCPA cements with hardening liquid composed of the PHYT as organic phosphate source, the polymeric CMC/ PAA polyelectrolytes for improving injectability and the fungal phytase for partial enzyme degradation of PHYT which affects cement setting process. The selected anionic organic additives contain carboxylate groups which-similar to PHYT acid—can interact with calcium in CPC and influence the microstructure formation. Moreover, we assume no mutual electrostatic interactions between individual organic compounds in hardening liquid due to their negative charge from which the relative high long-term stability of hardening liquid results.

\section{Materials and Methods}

\subsection{Preparation of Cement Mixtures and Cement Pastes}

The tetracalcium phosphate/monetite powder mixture (TMPM) was prepared by milling of TTCP in diluted solution of orthophosphoric acid ( $86 \%$ analytical grade, Merck, Darmstadt, Germany) in 80\% ethanol. The final $\mathrm{Ca} / \mathrm{P}$ mole ratio in TMPM equal to 1.67 (C cement-stoichiometric hydroxyapatite). Reaction milling was done in the planetary ball mill with agate balls ( 3 balls, $1 \mathrm{~cm}$ in diameter) and vessel for $30 \mathrm{~min}$. Tetracalcium phosphate $\left(\mathrm{Ca}_{4}\left(\mathrm{PO}_{4}\right)_{2} \mathrm{O}\right.$, TTCP) was synthesized by annealing of an equimolar mixture of calcium carbonate ( $\mathrm{CaCO} 3$, analytical grade, Sigma-Aldrich, Saint Louis, $\mathrm{MO}, \mathrm{USA}$ ) and dicalcium phosphate anhydrous (DCPA) $\left(\mathrm{CaHPO}_{4}\right.$ (Ph.Eur.), Fluka) at $1450{ }^{\circ} \mathrm{C}$ for $5 \mathrm{~h}$ with following milling in a planetary ball mill (Fritsch, $730 \mathrm{rpm}$, agate balls and vessel) for $2 \mathrm{~h}$. The phase purity was analyzed using X-ray powder diffraction analysis (XRD, Philips X Pert Pro, Malvern Panalytical B.V., Eindhoven, The Netherlands).

The cement pastes (CXI) (Table 1) were prepared by the mixing of TMPM powder mixture with $2 \%$ solution of sodium carboxymethyl cellulose (CMC, Sigma-Aldrich, sodium salt, $\mathrm{M}_{\mathrm{w}}=250 \mathrm{kDa}$ ) containing $0.5 \%$ or $1 \%$ of polyacrylic acid (PAA, Sigma-Aldrich, $\mathrm{M}_{\mathrm{w}}=100 \mathrm{kDa}, 35 \%$ solution.) and $8 \mathrm{wt} \%$ of phytic acid (PHYT) with addition of phytase (F3P, Natuphos ${ }^{\circledR}$, BASF, Ludwigshafen, Germany). Two P/L ratios equal 1.7 and 2 were used in experiments. The PHYT and F3P were separately dissolved in CMC/PAA solutions and mutually mixed for $60 \mathrm{~s}$. The final $\mathrm{Ca} / \mathrm{P}$ molar ratio (including phosphates in PHYT) was 1.50. The PHYT/F3P mass ratio was 20. The F3P was extracted from NATUPHOS ${ }^{\odot}$ phytase product in distilled water and after precipitation with ammonium sulfate ( $50 \%$ solution), was filtered and dialyzed (Millipore dialyzer, cut off $8 \mathrm{kDa}$ ) against distilled water for 4 days. The phytase activity determined according to [29] was $108 \mathrm{U} / \mathrm{mg}$ of enzyme.

Table 1. Composition of cement samples.

\begin{tabular}{ccc}
\hline Sample & P/L Ratio & PAA Content $/ \mathbf{w t} \%$ \\
\hline CXI1 & 1.7 & 0.5 \\
CXI2 & 2 & 0.5 \\
CXI3 & 1.7 & 1 \\
CXI4 & 2 & 1 \\
CX & 2 & free of PAA, CMC \\
C $^{*}$ & 2 & free of PAA, CMC, PHYT \\
\hline
\end{tabular}

${ }^{*} \% \mathrm{NaH}_{2} \mathrm{PO}_{4}$ hardening liquid. 


\subsection{Characterization Methods}

\subsubsection{Injectability, $\mathrm{pH}$ Measurement and Release of Ions from Cements during Soaking}

The changes in $\mathrm{pH}$ of simulated body fluid (SBF) solution during soaking of $600 \mathrm{mg}$ pellets $\left(0.5 \mathrm{~mm}\right.$ in thickness and $10 \mathrm{~mm}$ in diameter) $/ 15 \mathrm{~mL} \mathrm{SBF}$ after $24 \mathrm{~h}$ setting in $100 \%$ humidity at $37^{\circ} \mathrm{C}$ were measured using a pH-meter (WTW, Inolab 720) with the SenTix41 combined electrode. The CXI pellet of $500 \mathrm{mg}$ weight was added to $15 \mathrm{~mL}$ of $0.9 \% \mathrm{NaCl}$ solution at $37^{\circ} \mathrm{C}$ after $10 \mathrm{~min}$ setting in $100 \%$ humidity and slowly mixed in mini-rotator (BioRS24, Biosan, Riga, Latvia) at speed of $2 \mathrm{rpm}$. The total concentrations of released calcium and phosphate ions in $\mathrm{NaCl}$ solutions were analyzed using ICP (Horiba Activa) at selected soaking times (4, 24 h, 3, 7 days) and the free phosphate ions were determined by the colorimetry as $\mathrm{P}-\mathrm{Mo}-\mathrm{V}$ complexes [30]. The $\mathrm{Ca} / \mathrm{P}$ ratio in CXI cements was determined by ICP after setting for 7 days in SBF solution at $37^{\circ} \mathrm{C}$ and dissolution of samples in $\mathrm{HNO}_{3}$ (analytical grade, $1+2$ ).

The injectability of cements was tested by the extrusion of cement paste from polypropylene syringe. Briefly, a $10 \mathrm{~mL}$ syringe with the nozzle inner diameter of $2 \mathrm{~mm}$ was filled with cement pastes (approximately $5 \mathrm{~mL}$ ) after mixing cement powder mixture with hardening liquid at a given $\mathrm{P} / \mathrm{L}$ ratio. The syringe was fixed vertically in a holder and the paste was extruded from syringe after $3 \mathrm{~min}$ from addition of hardening liquid to cement using a universal testing machine (LR5K Plus, Lloyd Instruments Ltd., West Sussex, UK) at a crosshead speed of $10 \mathrm{~mm} / \mathrm{min}$ up to achievement of $100 \mathrm{~N}$ load limit. The cement injectability \% represents the relative mass amount of extruded paste to origin mass of cement paste in a syringe. The injectability was expressed as mean $\pm \operatorname{SD}(n=4)$.

\subsubsection{Compressive Strength, Phase Analysis, Setting Time and Microstructure of CXI Cements}

The injectable CXI cement pastes were molded into the shape of a cube $(10 \times 10 \times 10 \mathrm{~mm})$ for measurement of compressive strength by packing in plastic 3D printed form. The pastes were introduced to a $5 \mathrm{~mL}$ syringe, injected to prepared plastic forms and hardened in $100 \%$ humidity at $37^{\circ} \mathrm{C}$ for $30 \mathrm{~min}$. The following samples were immersed in simulated body fluid (SBF) solution at $\mathrm{pH}=7.4$ and $37^{\circ} \mathrm{C}$ and soaked for 7 days. The compressive strength ( 5 samples) was measured after demolding samples on a universal testing machine (LR5K Plus, Lloyd Instruments Ltd. West Sussex, UK) at a crosshead speed of $1 \mathrm{~mm} / \mathrm{min}$. The phase composition of samples was analyzed by X-ray diffraction analysis (Philips X' PertPro, using $\mathrm{Cu} \mathrm{K} \alpha$ radiation, Malvern Panalytical B.V., Eindhoven, Netherlands) and FTIR spectroscopy (Shimadzu, Kyoto, Japan, IRAffinity1, $400 \mathrm{mg} \mathrm{KBr}+1 \mathrm{mg}$ sample).

The microstructure of cements was observed by field emission scanning electron microscopy (JEOL FE SEM JSM-7000F, Tokyo, Japan). The final setting time of cement pastes was evaluated according to ISO standard 1566 [31] (Vicat method). The porosity of samples was calculated from measured dimensions and weight of samples. The theoretical density of hydroxyapatite $\left(3.15 \mathrm{~g} / \mathrm{cm}^{3}\right)$ was used for calculation.

\subsubsection{Cytotoxicity of Extracts, Viability Testing and ALP Activity of Osteoblasts, Live/Dead Staining}

The CXI pastes were prepared with hardening liquid and embedded in a sterile $50 \mathrm{~mL}$ polypropylene centrifuge tube with the complete osteogenic differentiation culture medium (the $\alpha$-modification Minimum essential medium Eagle (10\% FBS with osteogenic supplements L-ascorbic acid $50 \mu \mathrm{g} / \mathrm{mL}$, $50 \mathrm{nM}$ Dexametasone, $10 \mathrm{mM} \beta$-glycerophosphate and $1 \%$ penicillin, streptomycin, amphotericin (Sigma-Aldrich)) in a ratio of $0.2 \mathrm{~g}$ cement powder per $\mathrm{mL}$ of medium (A) (in accordance with ISO 10993-12:2012 [32]) and 0.1 g cement/mL medium (B1) in the case of long-term testing (9 and 15 days). The CXI pastes samples were prepared also in basic medium EMEM without osteogenic supplements according to the same method described above for long-term testing (B2, $0.1 \mathrm{~g} / \mathrm{mL})$.

Samples were soaked in medium in an incubator at $37^{\circ} \mathrm{C}$ for $24 \mathrm{~h}$ and subsequently, the cytotoxicity of A extracts was tested according to ISO 10993-5:2009 [33]. MC3T3E1 cells were harvested from culture flasks by enzymatic digestion and resuspended in culture medium. The cell suspension was adjusted at 
a density of $1.0 \times 10^{5}$ cells $/ \mathrm{mL}$. Briefly, $1.0 \times 10^{4}$ of pre-osteoblastic MC3T3E1 (Subclone 4) cells (ATCC CRL- 2593, Manassas, VA, USA) cells were suspended in $100 \mu \mathrm{L}$ of EMEM $+10 \%$ FBS, $1 \%$ antibiotic solution and seeded into each well of the 96-well cell Grade Brand microplate (adherent wells) and cultured to a semi-confluent monolayer at $37{ }^{\circ} \mathrm{C}, 95 \%$ humidity, and $5 \% \mathrm{CO}_{2}$ in an incubator for $24 \mathrm{~h}$. Subsequently, the culture medium in wells was replaced with $100 \mu \mathrm{L}$ of $100 \%$ extract (A, B1 and B2). All experiments were carried out in triplicate and cells in wells with extract-free complete culture medium were considered as a negative control. After $24 \mathrm{~h}$ of culturing, the A extracts were replaced with fresh culture medium and the in vitro cytotoxicity was evaluated by the MTS proliferation test assay (Cell titer 96 aqueous one solution cell proliferation assay, Promega, Promega Corporation, Madison, WI, USA). The absorbance of formazan was determined by a UV-VIS spectrophotometer (Shimadzu). The B1 and B2 extracts were used for long time osteoblast viability testing where culture extracts were exchanged every two days.

The CXI pastes for contact cytotoxicity assessment were prepared with hardening liquid and molded to a disc form ( $10 \mathrm{~mm}$ in diameter, $0.5 \mathrm{~mm}$ in height) and hardened in $100 \%$ humidity at $37^{\circ} \mathrm{C}$ for $24 \mathrm{~h}$ in an incubator. Samples were sterilized three times at $105^{\circ} \mathrm{C}$ for $45 \mathrm{~min}$. In total, $2 \times 10^{4}$ pre-osteoblastic MC3T3E1 (Subclone 4 cells) (ATCC CRL- 2593, Manassas, VA, USA) were seeded in $0.4 \mathrm{~mL}$ of culture medium (EMEM, $10 \%$ FBS) on cement surfaces in 48 well culture plates and cultured at $37^{\circ} \mathrm{C}$ in $\mathrm{CO}_{2}$ incubator.

The ALP activity of osteoblasts was determined in cell lysates after lysis in solution containing $0.1 \%$ Triton X-100, $1 \mathrm{mM} \mathrm{MgCl}_{2}$ a $20 \mathrm{mM}$ Tris. The cell lysates were transferred into $1.5 \mathrm{~mL}$ microcentrifuge polypropylene tubes, frozen at $-20{ }^{\circ} \mathrm{C}$ and centrifuged at $10,000 \mathrm{rpm}$ for $10 \mathrm{~min}$ after thawing. The $100 \mu \mathrm{L}$ of cell supernatant was added to $100 \mu \mathrm{L}$ of p-nitrophenyl phosphate in diethanolamine buffer $\left(0.5 \mathrm{mM} \mathrm{MgCl}_{2}, \mathrm{pH} 9.8\right)$ and incubated at $37^{\circ} \mathrm{C}$. The reaction was stopped after $60 \mathrm{~min}$ with $50 \mu \mathrm{L}$ of $3 \mathrm{M} \mathrm{NaOH}$. The amount of p-nitrophenol produced during the ALP enzyme catalysis of the p-nitrophenyl phosphate substrate was determined from the calibration curve of p-nitrophenol at $405 \mathrm{~nm}$ using the UV VIS spectrophotometer. The ALP activities were expressed in nanomoles of the p-nitrophenol produced per 1 min per microgram of proteins. The content of proteins in lysates was evaluated by Bradford's method with Coomasie blue G250 as the complexing agent [34]. The statistical evaluation of results $(n=4)$ was performed using one-way and two-way ANOVA analysis at level $\alpha=0.05$ (Statmost program).

The distribution and morphology of cells cultured in tested extracts and on discs were visualized with live/dead staining (fluorescein diacetate/propidium iodide) by fluorescent microscopy (Leica DM IL LED, Heerbrugg, Switzerland).

Alizarin red S staining of deposits after culture of osteoblasts in cement extracts was carried out after washing wells with PBS, fixing in ethanol for $10 \mathrm{~min}$ and final double washing with deionized $\mathrm{H}_{2} \mathrm{O}$. Deposits were stained with Alizarin red S staining solution for $30 \mathrm{~min}$. After removal of staining, solution wells were washed four times with water and observed under light microscope (Leica DM IL LED). Calcium deposits produced by cells were stained bright red. For quantitative analysis of deposits production by osteoblasts in different extracts, the calcium concentration in wells after the Alizarin red staining was determined by ICP. Calcium deposits were dissolved in $\mathrm{HNO}_{3}$ $(1+2$, analytical grade, Sigma-Aldrich) before analysis.

\subsubsection{Gene Expression}

For the extraction of total RNA we used approximately $1 \times 10^{6}$ cells. Total RNA from each cell culture was extracted using the RNeasy Mini Kit (Qiagen, Germantown, MD, USA) following the manufacturer's instructions. Contaminating genomic DNA was digested using the RNase-free DNase set (Qiagen, Germantown, MD, USA). The RNA quality and yields were analyzed using the Nanodrop spectrophotometer (Thermo Scientific, Waltham, MA, USA). Complementary DNA (cDNA) synthesis was performed using the protocol for RT2 First Strand Kit (Qiagen, Germantown, MD, USA), 
where $1 \mu \mathrm{g}$ of total RNA was used (after the genomic DNA elimination step) to prepare $20 \mu \mathrm{L}$ of cDNA. cDNA was then used for real-time PCR experiments.

The quantification of genes of interest in the cDNA samples was performed using primers for IGF1, osteocalcin and osteopontin (Table 2).

Table 2. Forward and reverse primers of genes used for RT-qPCR experiments.

\begin{tabular}{clcc}
\hline Gene & \multicolumn{1}{c}{ Primers $\left(\mathbf{5}^{\prime}-\mathbf{3}^{\prime}\right)$} & Length $(\mathbf{b p})$ & Reference \\
\hline \multirow{2}{*}{ B-actin mouse } & $\begin{array}{l}\text { F: CTCTGGCTCCTAGCACCATGAAGA } \\
\text { R:GTAAAACGCAGCTCAGTAACAGTCCG }\end{array}$ & 200 & [35] \\
Osteocalcin mouse & $\begin{array}{l}\text { F: AGCAGGAGGGCAATAAGGTAGT } \\
\text { R: TCGTCACAAGCAGGGTTAAGC } \\
\text { Osteopontin mouse }\end{array}$ & 118 & [36] \\
& R: CATTCTCTGGCAGCTCAGAGGA & 110 & {$[36]$} \\
\hline
\end{tabular}

A $25 \mu \mathrm{L}$ reaction mixture, each consisting of triplicate samples of cDNA, specific primer mix and RT2 SYBR Green qPCR mastermix (Qiagen, Germantown, MD, USA) was set up in each well of a 96 reaction plate (Roche, Switzerland). cDNA for $\beta$-actin was used as endogenous control for calculating fold differences in RNA levels of cells treated vs. not treated by biomaterials by the 2- $\Delta \Delta C T$ method. The plate was sealed using optical adhesive cover (Roche, Switzerland) and was placed in LightCycler 480 II real-time PCR system machine (Roche, Switzerland). The real-time PCR was performed under the following conditions: initial incubation at $95^{\circ} \mathrm{C}$ for $10 \mathrm{~min}$, amplification in 45 cycles at $95^{\circ} \mathrm{C}$ for $15 \mathrm{~s}$ followed by $60^{\circ} \mathrm{C}$ for $1 \mathrm{~min}$. Amplification specificity was checked by the generation of a melting curve. The statistical evaluation of results was performed using two-way ANOVA analysis at level $\alpha=0.05$ (Statmost program).

\section{Results}

\subsection{XRD and FTIR Analysis}

In Figure 1a, the XRD patterns of CXI cements after 7 days soaking at $37^{\circ} \mathrm{C}$ in SBF are shown. The final product of calcium phosphate cement transformation was calcium deficient nanocrystalline hydroxyapatite with a small carbonate substitution (HAP) (ICDD standard PDF4 01-071-5048). In CXI cements, a strong reduction in the amount of untransformed TTCP phase (JCPDS 25-1137) originated from starting cement mixtures (from about 23 to $7 \%$ and from $12 \%$ to traces of origin TTCP amount in cement with $1 \%$ of PAA and $0.5 \%$ of PAA respectively) with decreasing P/L was demonstrated. Moreover, the remains of monetite phase (lines from reflections of $(020),(-220)$ and $(-112)$ monetite planes, JCPDS09-0080) were clearly visible in CXI cement with 1\% PAA. The crystallinity sizes in CXI cements calculated from the Scherer's equation (from the reflection of (002) plane of HAP) were close to $38 \mathrm{~nm}$ except for CXI1 cement where the crystallinity size was around $24 \mathrm{~nm}$. No additional lines from any secondary phases were identified in patterns. The formation of calcium-deficient hydroxyapatite also verified chemical analysis of CXI cement after $24 \mathrm{~h}$ setting in $\mathrm{SBF}$, where the $\mathrm{Ca} / \mathrm{P}_{\text {free }}$ ratio and total $\mathrm{Ca} / \mathrm{P}$ ratio were $1.60 \pm 0.04$ and $1.54 \pm 0.02$ respectively.

FTIR spectra of $\mathrm{C}$ cement using $2 \% \mathrm{NaH}_{2} \mathrm{PO}_{4}$ hardening liquid, $\mathrm{CX}$ cement after setting in PBS at $37^{\circ} \mathrm{C}$ for 7 days; CXI4 cements setting in $100 \%$ humidity and soaking in PBS solution at $37^{\circ} \mathrm{C}$ for $24 \mathrm{~h}$ and 7 days respectively are shown in Figure $1 \mathrm{~b}$. In the IR spectra of all cements, antisymmetric $\left(v_{3}\right)$ and symmetric $\left(v_{1}\right) \mathrm{P}-\mathrm{O}$ stretching vibrations of $\mathrm{PO}_{4}{ }^{3-}$ group in hydroxyapatite located at 1090, 1033 and $962 \mathrm{~cm}^{-1}, \mathrm{O}-\mathrm{P}-\mathrm{O}$ bending $\left(v_{4}\right)$ vibrations at 565 and $602 \mathrm{~cm}^{-1}$ and librational mode of $\mathrm{OH}$ group in HAP around $630 \mathrm{~cm}^{-1}$ were found $[37,38]$. Bands characteristic for $v_{3}$ and $v_{2}$ vibrations of $\mathrm{CO}_{3}{ }^{2-}$ group in carbonated HAP at about 1460, 1420 and $870 \mathrm{~cm}^{-1}$ represent the B-type $\mathrm{CO}_{3}{ }^{2-}$ substitution for $\mathrm{PO}_{4}{ }^{3-}$ groups in HAP [39]. The low intense peak from stretching vibrations of the $\mathrm{OH}$ group in hydroxyapatite was identified at around $3570 \mathrm{~cm}^{-1}$. The peak at about $860 \mathrm{~cm}^{-1}$ found in the spectrum of CXI4 cement arises from vibrations of the hydrogen phosphate group in HAP [39,40] or a labile 
carbonate environment [41]. Besides the comparison of FTIR TTCP bands between 900 and $980 \mathrm{~cm}^{-1}$ with the same bands of deconvoluted CXI spectrum, peaks at 940, 947, 955 and $962 \mathrm{~cm}^{-1}$ from $v_{1}$ symmetric stretching vibration of $\mathrm{PO}_{4}$ group in TTCP [42] were clearly identified in spectrum. This fact is in accordance with the XRD analysis of CXI patterns.

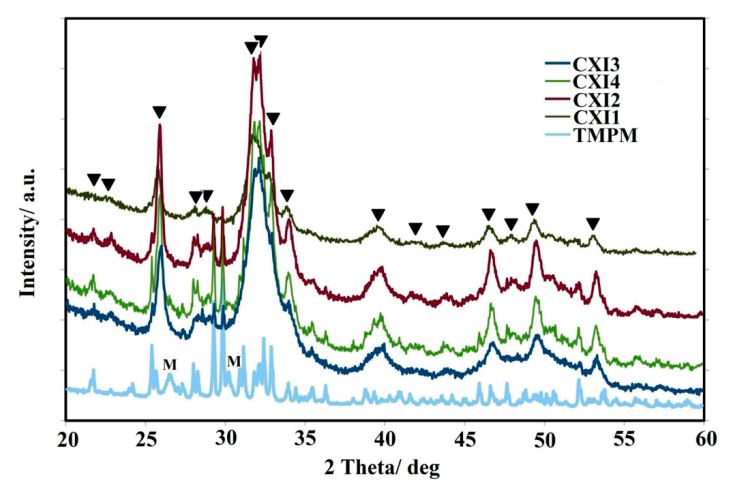

(a)

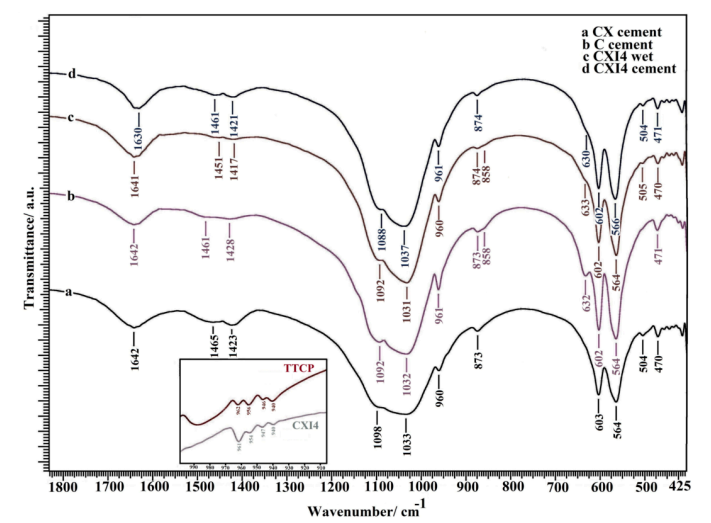

(b)

Figure 1. X-ray powder diffraction (XRD) patterns of CXI cements after 7 days soaking at $37{ }^{\circ} \mathrm{C}$ in simulated body fluid (SBF) (M-monetite, $\mathbf{v} \mathrm{HAP}$ ) (a) and FTIR spectra of C cement using $2 \% \mathrm{NaH}_{2} \mathrm{PO}_{4}$ hardening liquid, CX cement after setting in PBS at $37^{\circ} \mathrm{C}$ for 7 days; CXI4 cements setting in 100\% humidity and soaking in PBS solution at $37^{\circ} \mathrm{C}$ for $24 \mathrm{~h}$ and 7 days respectively (b).

No stronger FTIR bands in spectra of CXI cements corresponding to Ca-PHYT complexes at 1134, 996 and $842 \mathrm{~cm}^{-1}$ [43] were found after soaking in PBS solution or hardening in $100 \%$ humidity at $37^{\circ} \mathrm{C}$.

\subsection{Microstructure and Particle Morphology in CXI Cements}

The microstructure of CXI cements, as well as more detailed images of particle morphology after 7 days of setting cements in SBF solution at $37^{\circ} \mathrm{C}$, are shown in Figure 2. From the comparison, larger differences in HAP particle morphologies can be seen with the change in $\mathrm{P} / \mathrm{L}$ ratio than in the content of PAA in CXI cements, which are visible in images. Thus, the higher portion of needle-like hydroxyapatite particles can be seen in CXI cements at $\mathrm{P} / \mathrm{L}=1.7$ (Figure $2 \mathrm{a}, \mathrm{c}$ ) contrary to cements at $\mathrm{P} / \mathrm{L}=2$ where very fine mainly globular particles were found (Figure $2 \mathrm{~b}, \mathrm{~d}$ ). The needle-like HAP nanoparticles were joined in the form of spherical agglomerates about 1-5 $\mu \mathrm{m}$ size in CXI1 cement whereas the mixture of irregularly shaped strongly microporous agglomerates (around $1 \mu \mathrm{m}$ size) composed of fine globular nanoparticles $(<100 \mathrm{~nm}$ size) and thin needle-like submicron particles were revealed in the CXI3 sample by SEM. Note that the individual agglomerates were partially separated by a gap of micropores (up to $2 \mu \mathrm{m}$ ) in the CXI1 sample while such a boundary was significantly thinner $(<1 \mu \mathrm{m})$ and not so sharply distinguished in CXI3. The irregularly shaped micropores had the length of a few micrometers. The TEM images clearly verified observations from the SEM analysis, the length of needle-like HAP particles were up to $200 \mathrm{~nm}$ and $100 \mathrm{~nm}$ (thickness around $20 \mathrm{~nm}$ in both cements) for CXI1 and CXI3 samples respectively. Moreover, very fine $10 \mathrm{~nm}$ globular particles joined to agglomerates and mixed with needle-like particles were identified in TEM images of both cements too (Figure 2, for example).

In the case of CXI cements with $\mathrm{P} / \mathrm{L}=2$, the hydroxyapatite agglomerates of $5-10 \mu \mathrm{m}$ size composed of submicrometric globular particles were identified in microstructures (Figure 2b,d). A relatively high fraction of irregularly shaped micropores of up to $10 \mu \mathrm{m}$ size was revealed in both cements but no clearly visible separation of agglomerates was visible in images from which resulted that a more compact microstructure was formed during the hardening of cements. If we compared the morphology of HAP particles observed using TEM, the significant particle refinement was found in 1\%PAA CXI4 cement where the diameter of spherical particles did not exceed $10 \mathrm{~nm}$ contrary to the dimension of particles in the form of rods (up to $50 \mathrm{~nm}$ ) in CXI2 sample (Figure 2f,h). Rods were mutually 
mixed with a lower portion of the finer spherical nanoparticles in CXI2 cement. Note that the SAED (selected area electron diffraction) analysis confirmed the formation of hydroxyapatite particles in all hardened cements.
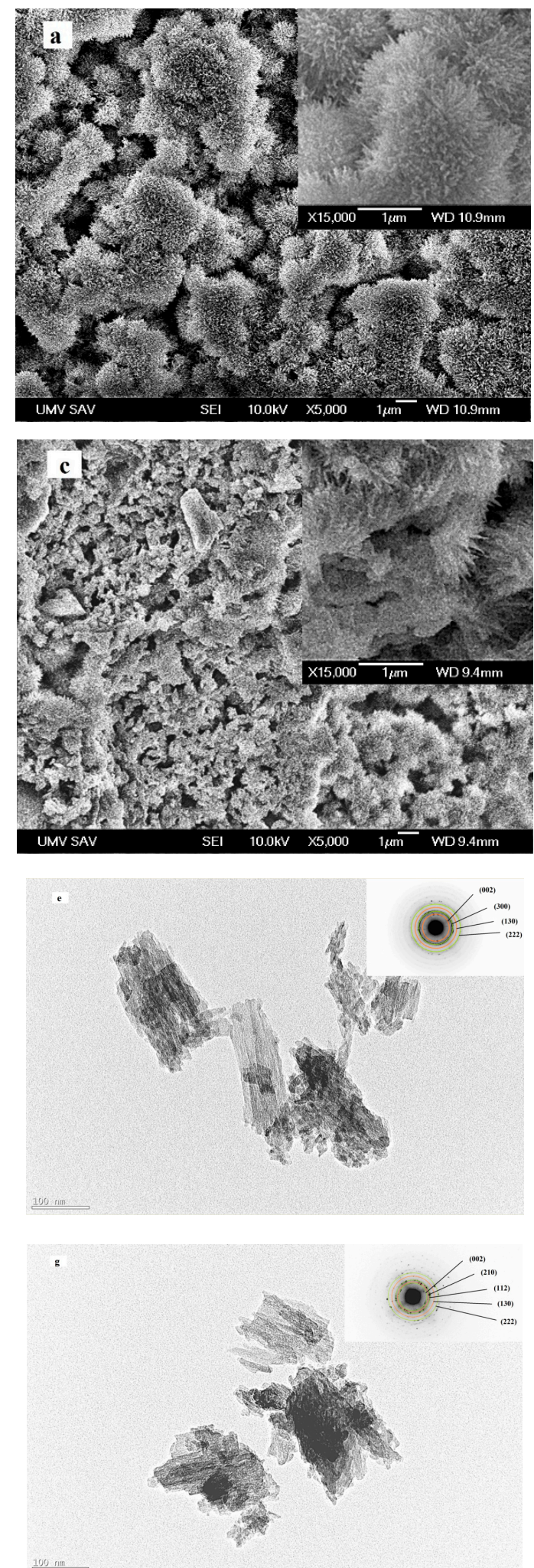
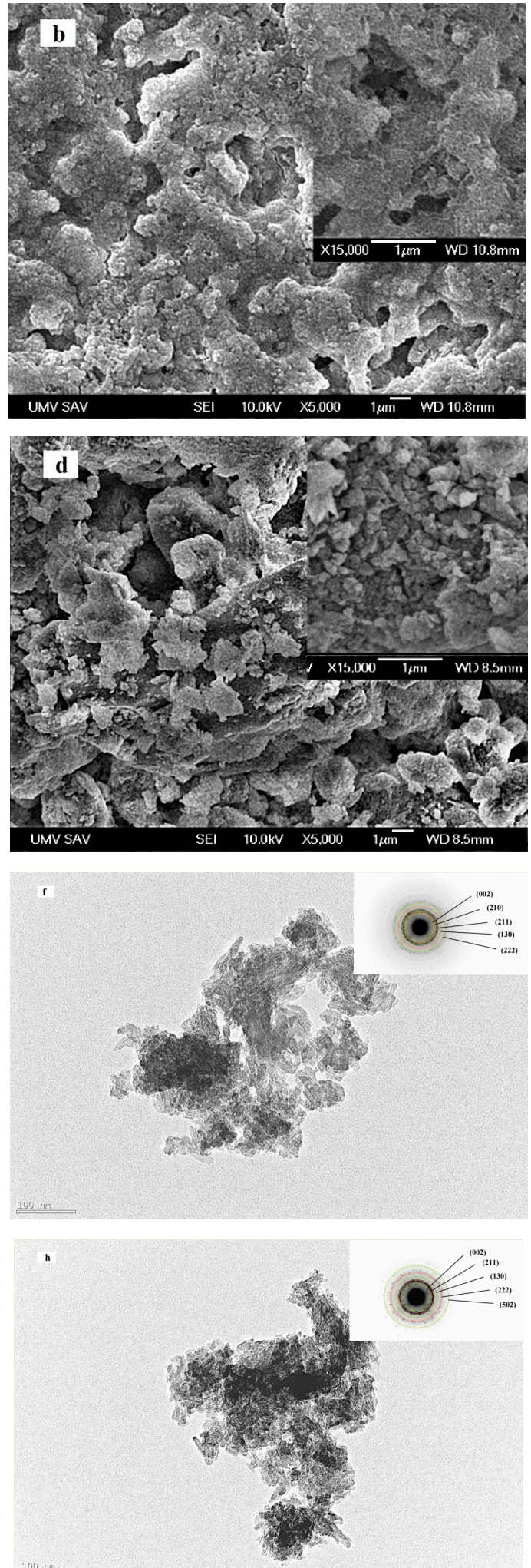

Figure 2. Microstructure of CXI cements and particle morphology after 7 days setting in SBF solution at $37^{\circ} \mathrm{C}(\mathbf{a}, \mathbf{e}-\mathrm{CXI} 1, \mathbf{b}, \mathbf{f}-\mathrm{CXI} 2, \mathbf{c}, \mathbf{g}-\mathrm{CXI} 3, \mathbf{d}, \mathbf{h}-\mathrm{CXI} 4)$. 
Results from the relative density analysis (RD) of hardened cements clearly showed the rise in RD from $44 \%$ to $49 \%$ with the $\mathrm{P} / \mathrm{L}$ ratio while the content of PAA in cements had an insignificant effect on RD.

\subsection{Analysis of Ion Release, pH Measurement, Compressive Strength, Setting Time and Injectability}

The release of calcium and phosphate ions and the change in $\mathrm{pH}$ values with soaking time of CXI cements in $0.9 \% \mathrm{NaCl}$ and SBF solutions respectively are depicted in Figure 3. Much higher concentrations of $\mathrm{Ca}$ and phosphorus were verified in $\mathrm{NaCl}$ solution with $1 \% \mathrm{PAA}$ cement at the $\mathrm{P} / \mathrm{L}$ ratio $=2$ as compared with these ones at $\mathrm{P} / \mathrm{L}=1.7$ while only insignificant differences in concentration of both species with the $\mathrm{P} / \mathrm{L}$ ratio were identified in $\mathrm{NaCl}$ solution containing $0.5 \%$ cements. On the other side, the release of elements depended on the content of PAA in cements, especially during the first $24 \mathrm{~h}$ of soaking where the concentration of $\mathrm{Ca}$ and $\mathrm{P}$ was significantly higher in solutions with $1 \%$ PAA cements at $\mathrm{P} / \mathrm{L}=2$ as well as an enhanced content of $\mathrm{P}$ was found in solution with $1 \%$ PAA cement at $\mathrm{P} / \mathrm{L}=1.7$ (statistically significant difference, $p<0.05$ ) (Figure $3 \mathrm{a}, \mathrm{b}$ ). The Ca concentration achieved maximum after $72 \mathrm{~h}$ soaking CXI cements at $\mathrm{P} / \mathrm{L}=2$ and gradually decreased whereas the $\mathrm{P}$ concentration gradually decreased after 24 h soaking cements at $\mathrm{P} / \mathrm{L}=1.7$. Simultaneously with the above-presented changes, a slow increase in $\mathrm{pH}$ up to 8 was observed at the time period when the $\mathrm{Ca}^{2+}$ concentration rose contrary to the $\mathrm{P}$ concentration (Figure $3 \mathrm{c}$ ).

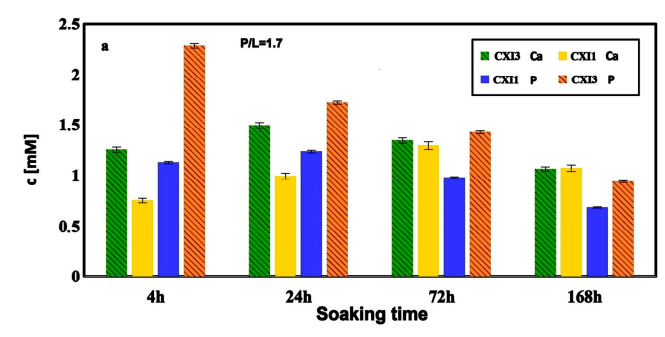

(a)

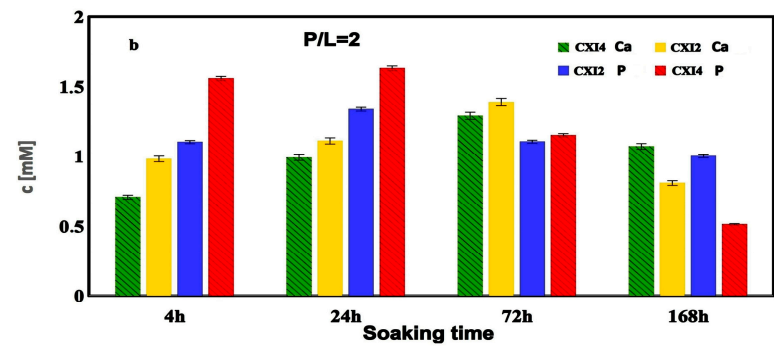

(b)

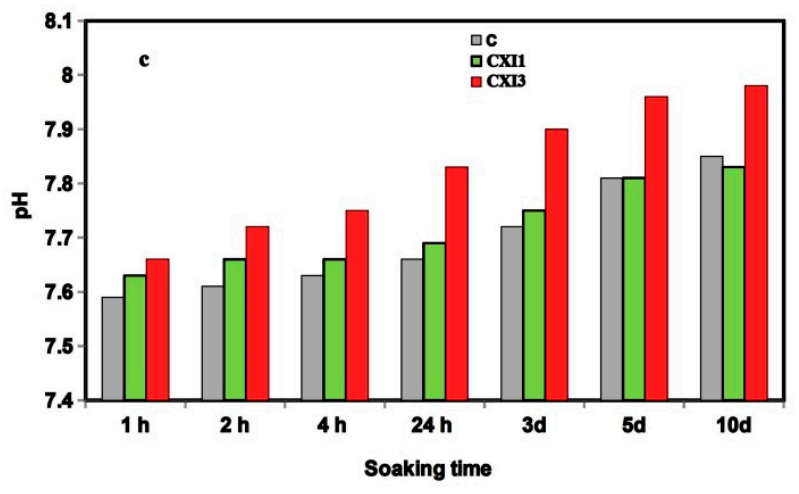

(c)

Figure 3. Release of calcium and phosphate ions $(\mathbf{a}, \mathbf{b})$ and change in $\mathrm{pH}$ values (c) with soaking time of CXI cements in $0.9 \% \mathrm{NaCl}$ and $\mathrm{SBF}$ solutions respectively.

The wet CS of CXI cement after setting in SBF for 7 days was influenced by the $\mathrm{P} / \mathrm{L}$ ratio, where the $\mathrm{CS}$ of $7 \pm 2 \mathrm{MPa}$ and $15 \pm 3 \mathrm{MPa}$ was measured for the P/L equal 1.7 and 2 respectively. None effect of the PAA content in cement on wet CS was identified. Similarly, the setting time of CXI cements was 
reduced from $28 \pm 1 \mathrm{~min}$ to $7 \pm 1 \mathrm{~min}$ with the rise in $\mathrm{P} / \mathrm{L}$ ratio from 1.7 to 2 . ST can be significantly reduced by the prolongation of the reaction time between PHYT and F3P during mixing of hardening liquid, e.g., ST of CXI3 cement fell down from 28 to $8 \mathrm{~min}$ for reaction times $30 \mathrm{~s}$ and $1 \mathrm{~min}$ respectively. Dry CS's of cements were around $22 \pm 3$ and $21 \pm 2 \mathrm{MPa}$ in CXI1 and CXI3 samples respectively, and rose in CXI2 and CXI4 cements to $29 \pm 4$ and $33 \pm 2$ MPa respectively at higher P/L. Note that all CXI cements were fully injectable regardless of the $\mathrm{P} / \mathrm{L}$ ratio but a more viscously paste was formed at the $\mathrm{P} / \mathrm{L}=2$.

\subsection{Evaluation of In Vitro Cytotoxicity of Extracts, Live/Dead Staining and Production of Ca Deposits by Osteoblasts in Extracts, Gene Expression of Markers}

The in vitro cytotoxicity testing of 100\% cement extracts (A) (according to ISO 10993-12:2012) clearly confirmed the noncytotoxic character of extracts (Figure 4a). No differences in the morphology of cells cultured on cement surfaces for $48 \mathrm{~h}$ in $\alpha \mathrm{MEM}$ were identified by live/dead staining (Figure 5) and on images are only visible live cells of globular poorly prolonged morphology adhered to cement surfaces. For the long-term cytotoxicity testing, 50\% cement extracts $(0.1 \mathrm{~g}$ cement $/ \mathrm{mL}$ medium $)$ in the osteogenic $\alpha$ MEM medium (B1) and MEM medium (B2) without any supplements were used for the culture of osteoblasts (we assume a relatively high dilution of species released from cements to body fluids after implantation).

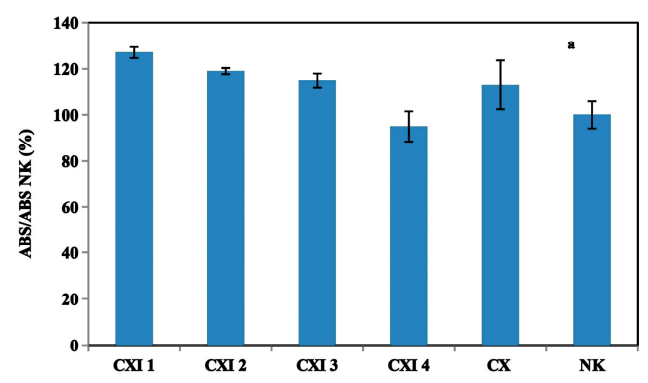

(a)

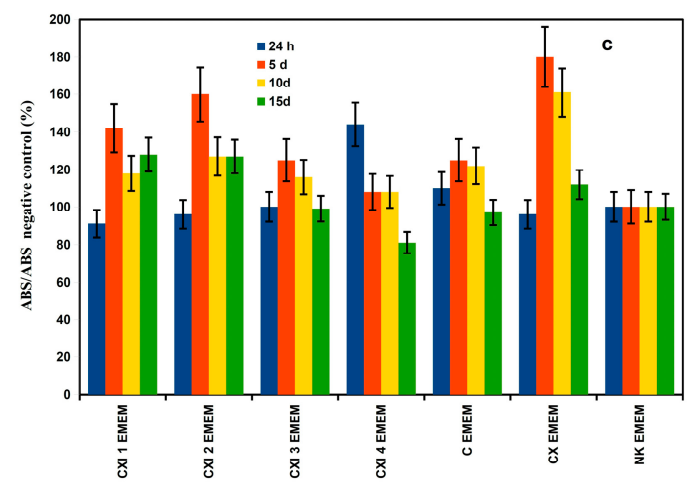

(c)

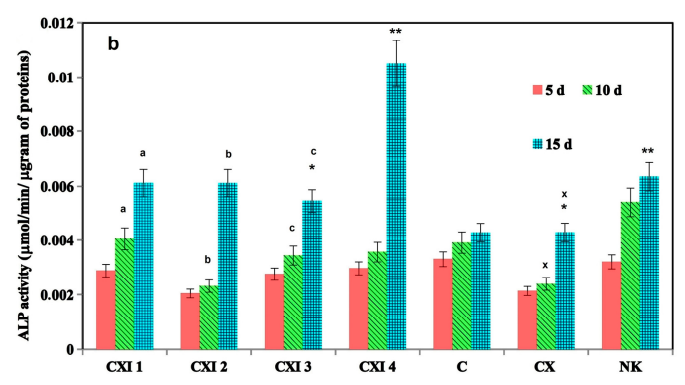

(b)

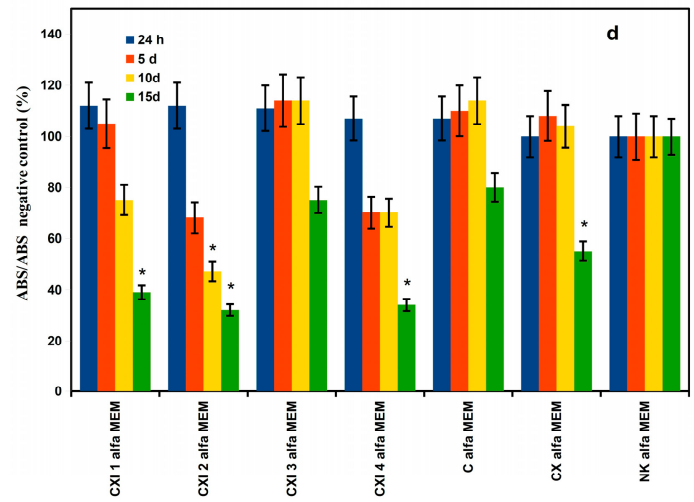

(d)

Figure 4. Relative viability of cells cultured in 100\% cement extracts (according to ISO 10993-12:2012) (a); ALP activity of osteoblasts cultured in 50\% $\alpha$ MEM CXI extracts (b) (statistically significant difference: a $\left.(p<0.006), \mathrm{b}(p<0.0005), \mathrm{c}(p<0.01), \mathrm{x}(p<0.05),{ }^{*}(p<0.015),{ }^{* *}(p<0.0002)\right)$ and dependence of relative viabitily of osteoblasts on culture time in 50\% EMEM (c) and $\alpha$ MEM (d) cement extracts (* under 70\% non-cytotoxic level of control, $p<0.05$ ). 

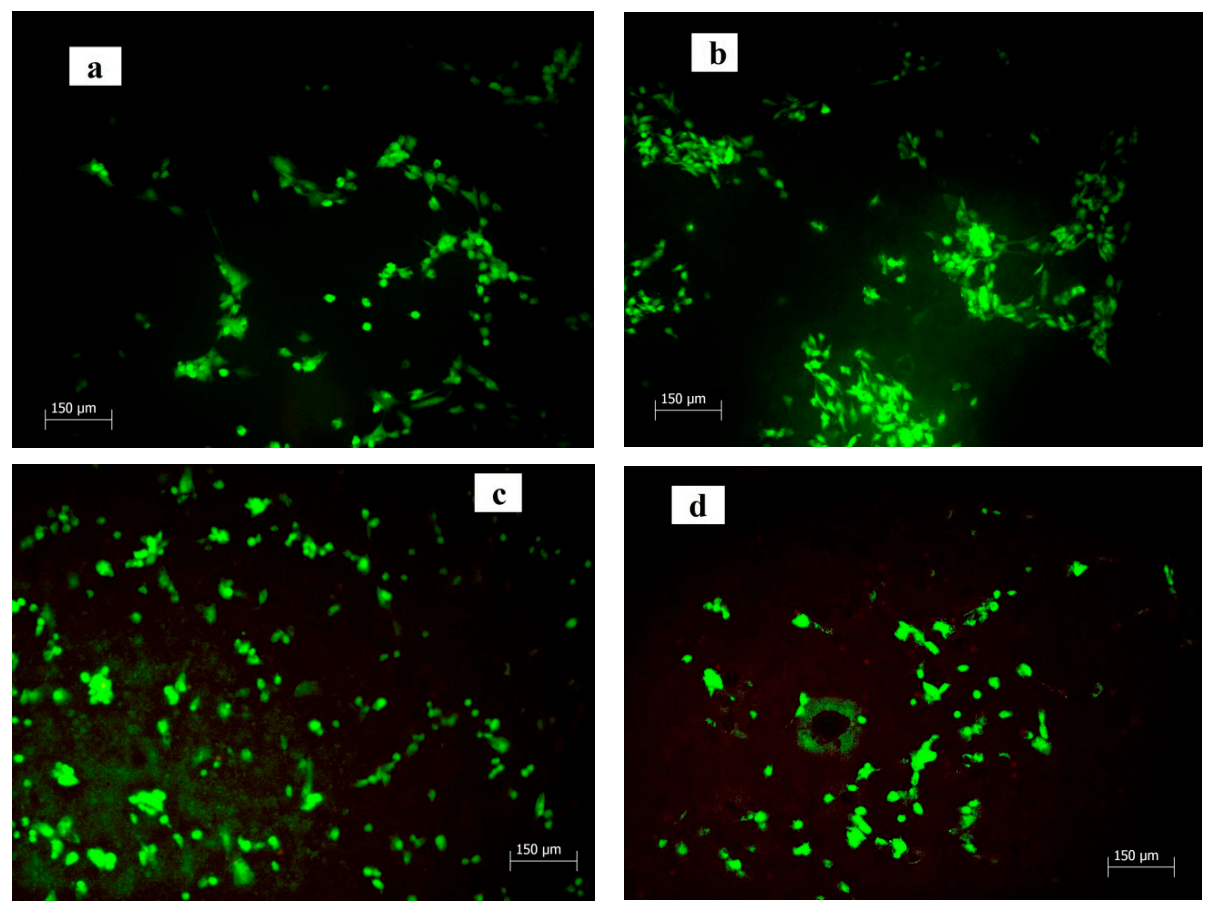

Figure 5. Morphology of cells cultured on cement surfaces for $48 \mathrm{~h}$ in $\alpha \mathrm{MEM}$ at $37^{\circ} \mathrm{C}$ (live/dead staining; $\mathbf{a}-\mathrm{C}$ cement, $\mathbf{b}-\mathrm{CX}$ cement, $\mathbf{c}-\mathrm{CXI1}$ cement, $\mathbf{d}-\mathrm{CXI} 3$ cement; magnification: $100 \times)$.

Dependences of the relative viability of osteoblasts on culture time in 50\% extracts (Figure 4c,d) revealed high viability of osteoblasts in the EMEM extracts free of osteogenic supplements regardless of the culture time contrary to viability in the osteogenic $\alpha$ MEM extracts where it was strongly reduced after 10 days of culture. After 15 days of culture in $\alpha$ MEM CXI extracts, the viability of osteoblasts decreased under 70\% non-cytotoxic level (according to ISO). From the comparison of ALP activities, it resulted that the ALP activity of osteoblasts in 50\% $\alpha$ MEM CXI extracts statistically significantly rose $(p<0.05)$ after 15 days of culture and it was significantly higher than the ALP activity of osteoblasts in the case of CX or C extracts (Figure 4d).

For the evaluation of the number of calcium deposits produced by osteoblasts in extracts, the concentration of calcium and phosphorus at selected culture times was determined after the dissolution of deposits in wells. While the concentration of calcium in wells increased with culture time in $50 \% \alpha$ MEM cement extracts especially after 6 days of culture (Figure $6 \mathrm{a}$ ), the content of phosphorus was very high during the first 6 days of cultivation in CXI extracts (Figure $6 \mathrm{~b}$ ). In the C extract and NK, the amount of phosphorus rapidly fell down (almost 10 times) even after 6 days of cultivation (Figure 6b). This tendency was observed in CXI extracts after 9 days of culture. The enhanced concentration of calcium was also measured in CXI EMEM extracts but the Ca concentration was much lower than in the $\alpha$ MEM extracts (3-10 times) (Figure $6 c$ ) as well as a very low amount of calcium deposits was produced by osteoblasts in the $\mathrm{C}$ extract. Note that the traces of phosphorus were identified in EMEM extracts $(<0.1 \mathrm{mM})$ by ICP only.

The formation of a large number of calcium deposits in 50\% $\alpha \mathrm{MEM}$ cement extracts is demonstrated by images after alizarin red staining (Figure 7). The deposits in wells were intensively red-stained due to the interaction of the dye with calcium deposits in CXI extracts after 15 days of cultivation. This result is in accordance with the rise in both the Ca content and ALP activity in CXI wells. It is clear from the comparison of the above facts that PHYT supported the formation of Ca deposits but the additional synergistic effect of PAA and CMC on enhanced ALP activity of CXI cements was verified. For verification of osteoblastic activity of cells, the osteogenic gene expressions for osteopontin, osteocalcin and IGF1 growth factor were evaluated by the RT-qPCR analysis. The relative gene expression (Figure 8) clearly demonstrated the strong up-regulation of IGF1, OC and OP in 
osteoblasts cultured for 14 days in $\alpha$ MEM 50\% CXI extracts (statistically significant difference) as compared with $\mathrm{C}$ samples and 7 days cultured cells in CXI cement extracts.

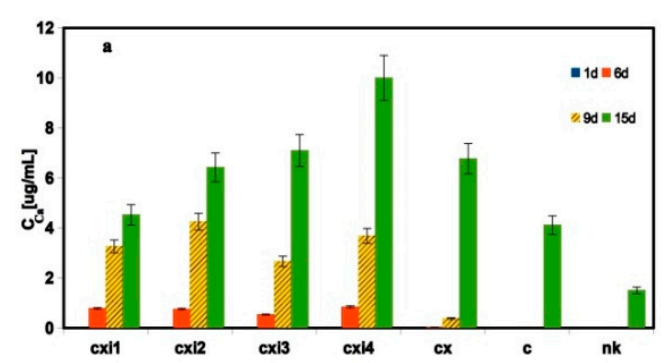

(a)

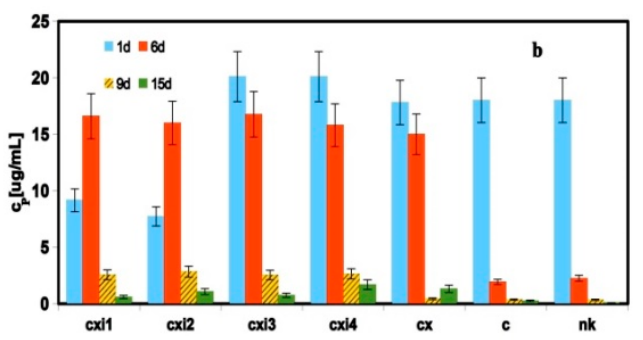

(b)

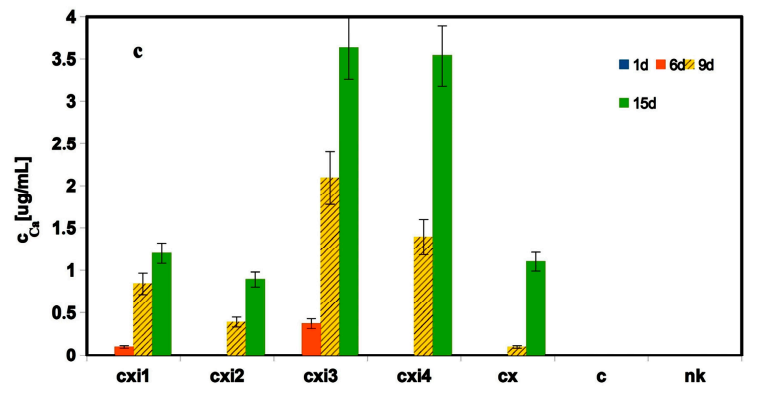

(c)

Figure 6. Concentration of calcium and phosphorus in deposits produced by osteoblasts cultured in wells for selected times in 50\% $\alpha \operatorname{MEM}(\mathbf{a}, \mathbf{b})$ and EMEM (c) CXI extracts.
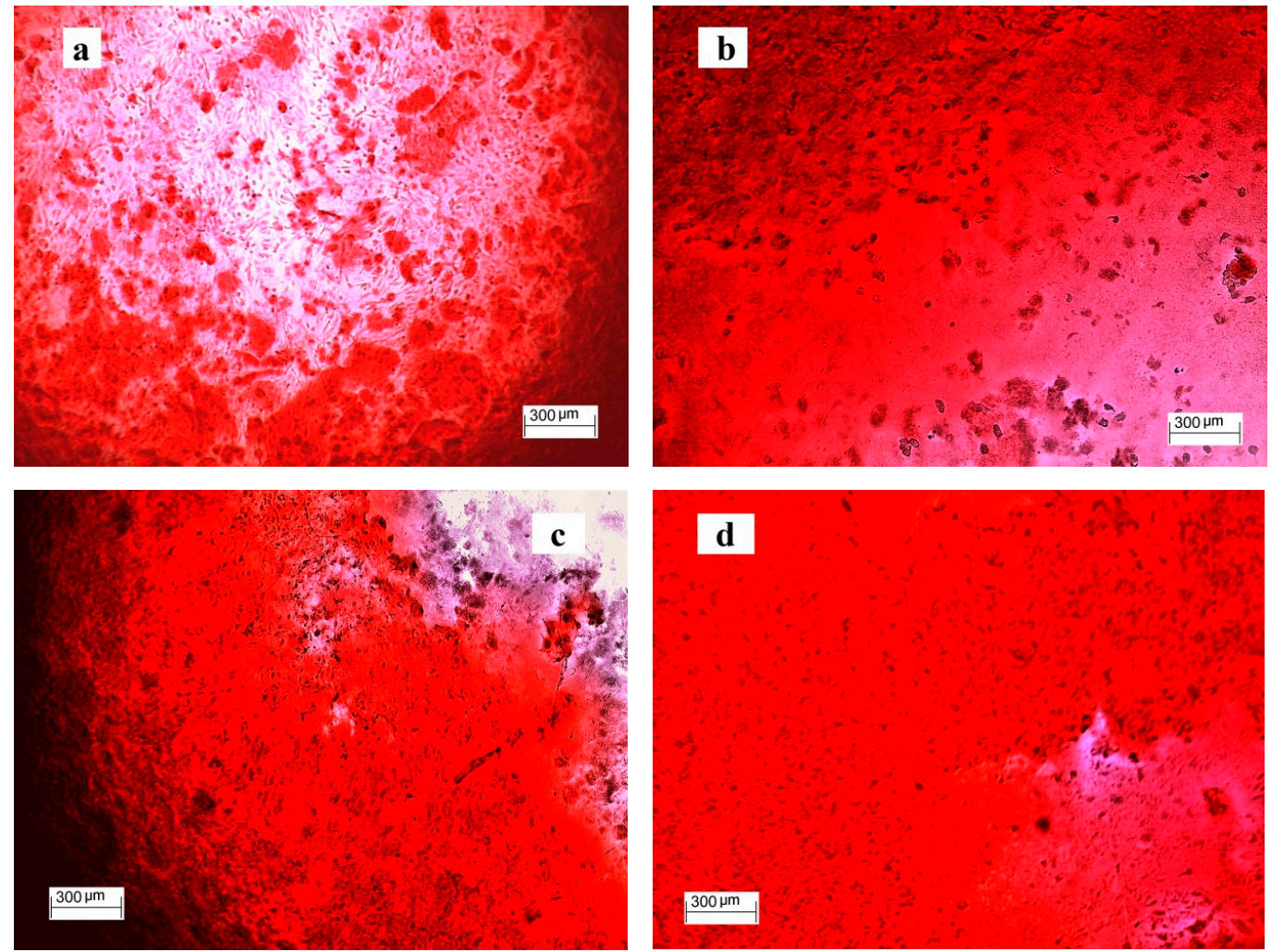

Figure 7. Formation of calcium deposits in wells after 15 days of culture of osteoblasts in $50 \% \alpha \mathrm{MEM}$ cement extracts (alizarin red staining; $\mathbf{a}-\mathrm{C}, \mathbf{b}-\mathrm{CX}, \mathbf{c}-\mathrm{CXI1}, \mathbf{d}-\mathrm{CXI} 3$ ). 


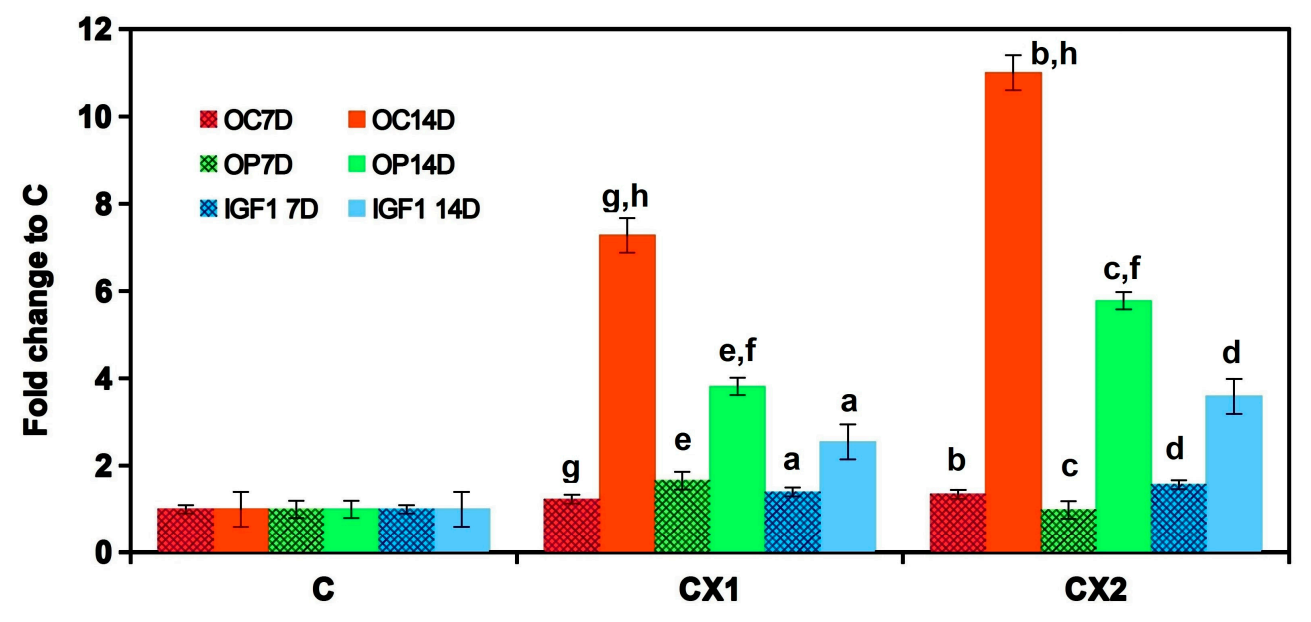

Figure 8. Relative gene expression from RT-qPCR analysis of cell lysates cultured for 7 and 14 days (statistically significant difference, $p<0.01)$ ).

\section{Discussion}

Based on chemical analysis and taking into account phosphates from PHYT or inositol phosphates in cements, the total $\mathrm{Ca} / \mathrm{P}$ ratio in CXI cement was close to the theoretical, and no soluble Ca complexes after interaction with inositol phosphates (with any numbers of phosphate groups) that remained were released from cements. Despite the fact that approximately $8 \mathrm{wt} \%$ of PHYT was added to cement, the intensity of phytate peaks in FTIR spectra of CXI cements was very weak and we believe that the intensity of peaks was lowered due to the delocalization of electrons after bonding with surface calcium ions. Note that an amount of the admixed CMC and PAA was very low for their identification in CXI spectra but no mutual interaction including the PHYT is possible because of the dissociation of carboxylic and phosphate groups in compounds with following net negative charge at $\mathrm{pH}>7$. Similar types of organic complexes are known, e.g., between chitosan and PAA or PHYT but these electrostatic interactions were the result of the opposite charge density of reactants [44,45].

It was revealed that the calcium phosphate mineralization and the particle morphology of carboxymethyl cellulose-grafted polymethacrylic acid templates can be affected by the preparation conditions [46,47]. In the (hydroxypropyl)cellulose or (ethyl)cellulose/PAA composite mineralized films, three various calcium phosphate forms-the amorphous calcium phosphate, hydroxyapatite, and the PAA- $\mathrm{Ca}^{2+}$ complex-were identified after incorporation of the calcium and phosphate ions inside the polymer matrices from soaking solution [48]. On the other hand, a strong inhibition effect of the PAA on apatite formation was found in bioactive glass-ionomer cements, and the presence of a small quantity of PAA in SBF hindered the apatite formation on AW glass ceramics [49]. Similar to the case of CXI cements, it was identified that the remains of TTCP and DCPA phases were found in XRD patterns of the TTCP/DCPA cement with $2 \%$ addition of CMC gel but a small difference was only verified in comparison with XRD patterns of pure cement [50]. These facts indicate that the polymeric additives create complexes on the surface of calcium phosphate particles which hinder the complete transformation of CXI cements. Simulations of HAP-polymer interfacial molecular interactions demonstrated that the most favorable orientation of PAA for the interaction with HAP is along the c-axis of HAP aligned parallel to polymer chains for in situ HAP, contrary to ex situ HAP/PAA composites where the (001) HAP surface is the most probable plane for adsorption of PAA molecules [51]. The change in HAP particle morphology from rod-like to spherical as well as the structural change from nanocrystalline to amorphous phase was observed with increasing content of the PAA from 0.3 to $0.5 \mathrm{mg} / \mathrm{mL}$ during precipitation [52]. Thus, the refinement of HAP particles at a higher PAA content in CXI cements as well as the rise of the spherical fraction at the expense of rod-like particles can be associated with the change in the type of PAA adsorption in relation to HAP planes. It can be assumed that while the (100) plane was preferable for PAA adsorption on 0.5 PAA CXI cement particles, which inhibits the growth of 
HAP in this plane and simultaneously supports the growth of HAP particles in (001) plane and the formation of needle-like particles in CXI microstructures, the PAA adsorption in (001) HAP plane or even in both planes was enhanced at $1 \mathrm{wt} \%$ PAA content in cements with the formation of very fine spherical particles. Moreover, the growth of HAP particles was influenced by the content of liquid phase in CXI cement microstructure where a lower content of liquid $(\mathrm{P} / \mathrm{L}=2)$ caused faster achievement of supersaturation and shortening of diffusion distances between individual cement particles with the acceleration of precipitation on nucleation sites and following re-crystallization. These facts are important, especially in the case of viscous liquids with lower values of diffusion coefficients of ions in CXI cements containing CMC where higher contents of liquid are responsible for the existence of a large number of HAP nuclei which are stabilized in colloidal state and creates globular very fine particles or agglomerates like in CXI2 and CXI4 cements. Similar stabilization of colloidal HAP particles was revealed during the precipitation in presence of CMC [53,54].

From previous work, we know that the formation of Ca-inositol phosphate complexes as well as the presence of free phosphates affects the growth of HAP particles into the form of columnar thin individually separated HAP particles, forming wells around hollows in microstructure [28]. No such morphological type of particles was documented in the microstructure of CXI cements which clearly demonstrates the strong influence of polymeric additives on particle growth and formation of CXI cement microstructure. On the other hand, the significant effect of PAA concentration was demonstrated during precipitation of HAP where a rise in PAA concentration from 0.3 to $0.5 \mathrm{mg} / \mathrm{mL}$ caused the structural change from nanocrystalline to amorphous phase [52].

$$
\begin{gathered}
3 \mathrm{Ca}_{4}\left(\mathrm{PO}_{4}\right)_{2} \mathrm{O}+3 \mathrm{H}_{2} \mathrm{O} \rightarrow \frac{2 \mathrm{Ca}^{2+}+4 \mathrm{OH}^{-}+2 \mathrm{Ca}_{5}\left(\mathrm{PO}_{4}\right)_{3} \mathrm{OH}}{\downarrow \leftarrow+\mathrm{PO}_{4}{ }^{3-}(\text { from PHYT })} \\
3 \mathrm{CaHPO}_{4}+\mathrm{H}_{2} \mathrm{O} \rightarrow 3 \mathrm{Ca}^{2+}+3 \mathrm{H}_{3} \mathrm{O}^{+}+3 \mathrm{PO}_{4}{ }^{3-} \\
\downarrow \\
\mathrm{Ca}_{5}\left(\mathrm{PO}_{4}\right)_{3} \mathrm{OH}+\mathrm{H}_{2} \mathrm{O}
\end{gathered}
$$

The comparison of results from the chemical analysis revealed that the amount of released $\mathrm{P}$ correlated with the content of PAA and PHYT in cements during the first stage of cement transformation (due to a higher addition of hardening liquid to cement (lower $\mathrm{P} / \mathrm{L}$ ratio)) but no statistically significant difference $(p<0.05)$ was identified between the concentration of free phosphate ions and total phosphates in solutions at the selected time. Thus, it can be assumed that more stable insoluble PHYT complexes were created on the surface of origin calcium phosphate particles but the local acid environment due to acid hardening liquid supported an enhanced solubility and hydrolysis of the origin calcium phosphate mixture as well as prolonged the enzyme activity of F3P with releasing phosphate ions from PHYT which are consumed during the formation of hydroxyapatite nanoparticles in the later stage of the cement transformation. From the point of view of practical applications, it is an interesting fact that the $\mathrm{pH}$ changes in CXI SBF solutions with soaking time were relatively slow after $1 \mathrm{~h}$ from the cement immersion with a maximum not exceeding 8 for CXI3 cement. The lower $\mathrm{pH}$ values found in SBF of CXI1 cement as compared to CXI3 can be related to the faster achievement of supersaturation in relation to hydroxyapatite in CXI3 solution due to stronger hydrolysis of TTCP with the following interaction with monetite according to Equations (1)-(3). From the equarions, it is clear that the result is that hydroxyl ions are gradually consumed with both the prolongation of cement transformation and the $\mathrm{pH}$ solution rise. The enhanced TTCP hydrolysis was supported by a higher concentration of phosphates produced in more acidic conditions in CXI3 cement due to $1 \%$ PAA content and deeper enzymatic attack of PHYT with phytase. The phosphate ions shift the chemical equilibrium to the product side due to the consumption of calcium ions which arise from TTCP hydrolysis (Equation (1)). 
The dependence of cement paste fluidity vs. the PAA/cement ratio was measured as a minimum but the high fluid paste was produced in an interesting region with $<5 \%$ PAA due to the adsorption of PAA on the surface of cement particles [55]. It was shown that the setting time of TTCP/DCPA cements with the PAA content between 10-25\% decreased with the PAA molecular weight to around $10 \mathrm{~min}$ for $\mathrm{M}_{\mathrm{w}} \sim 100 \mathrm{kDa}$. Similarly, the $\mathrm{CS}$ of cements containing a high molecular PAA was reduced in comparison with the standard cement and achieved about $20 \mathrm{MPa}$ for $10 \mathrm{wt} \%$ PAA cement $(100 \mathrm{kDa})$ [56]. The significant influence of TTCP/DCPA ratio on the CS of PAA cements due to cross-linking PAA via $\mathrm{Ca}$ ions was measured [57]. On the other side, the rise in addition of CMC to the brushite/vaterite cement up to $50 \mathrm{wt} \%$ caused the increase in dry composite CS to $86 \mathrm{MPa}$ as a result of cement porosity reduction [58]. The injectability (and cohesion) of $\alpha \mathrm{TCP}$ cement was improved by $1.5 \mathrm{wt} \%$ addition of CMC up to $90 \%$ while the setting time decreased from 11 to 7 min [59]. Contrary to the above facts, the injectability of $\alpha \mathrm{TCP}$ cements with admixing powder CMC was even reduced at lower contents of $\mathrm{CMC}(<1 \mathrm{wt} \%)$ as compared with the pure $\alpha \mathrm{TCP}$ cement due to the segregation of the solid phase from paste during extrusion but rose at higher CMC contents (twice than pure cement). Moreover, the insignificant effect of the CMC addition on $\mathrm{pH}$ was observed [60]. The higher CS (around $60 \mathrm{MPa}$ ) was found in TTCP/DCPA composite cement with the high PAA content (up to 25 $\mathrm{wt} \%)$ and simultaneous addition of tartaric acid/ $\mathrm{CaF}_{2}$ mixture but the ductile cements were prepared at $50 \mathrm{wt} \%$ content of PAA due to particle coating with polymer and the formation of brushite [21]. Setting times were controlled by the $\mathrm{P} / \mathrm{L}$ ratio in this case. A gradual transformation of $\alpha \mathrm{TCP}$ cement to hydroxyapatite after mixing with concentrated $\mathrm{PAA} / 2 \% \mathrm{Na}_{2} \mathrm{HPO}_{4}$ hardening solution was identified but the setting time was around $22 \mathrm{~min}$. CS and porosity of this composite cement did not exceed $22 \mathrm{MPa}$ and $30 \%$ respectively [61]. It was demonstrated that a $2 \%$ addition of CMC to TTCP/DCPA cement in gel form caused the fast cement resistance to washout $(<2 \mathrm{~min})$ but the CMC addition had no effect on the $\mathrm{CS}$ of cement composite (around $45 \mathrm{MPa}$ ) at $\mathrm{P} / \mathrm{L}=3.75$ [50]. In the case of CPC based on dicalcium phosphate with an addition of 5-20 wt $\%$ PHYT as hardening liquid, the CS achieved about $16 \mathrm{MPa}$ and the PHYT caused injectability of cements due to the retardation of the setting process [62]. On the other hand, cement powder in the form of HAP particles coated with PHYT, which was hardened with water, had the CS maximal of $10 \mathrm{MPa}$ [63].

From the comparison of results with the above papers, the CXI cements are characterized by similar or improved properties than in presented cements as, for example, the almost complete transformation to hydroxyapatite, the full injectability with the high resistance to washout in aqueous solutions in a short time after mixing, the sufficient value of CS comparable with bone tissue as well as the easily controllable setting process via interaction between PHYT and F3P whereas much lower amounts of organic poly-electrolytes were admixed to cements.

CXI extracts stimulated up-regulation in the expression of osteogenic genes. The high gene over-expression, especially OC (up to 11-fold) and OP (6-fold), relative to C extract corresponds with the large number of calcium deposits produced by osteoblasts in CXI extracts, thus, additives in CXI cements significantly supported the maturation and activity of osteoblasts. It is known that the IGF1 factor stimulates the type I collagen synthesis, osteocalcin production and alkaline phosphatase activity $[64,65]$. On other hand, the osteocalcin (OC) has been found to accelerate nucleation by promoting the growth of nanosized calcium phosphate ion clusters and suppressing hydroxyapatite crystal growth $[66,67]$ as well as osteopontin (OP) in mixture with osteocalcin-promoted hydroxyapatite formation [68]. Both proteins are induced in the mineralization stage and are characterized by mature osteoblasts [69]. Calcium phosphate-loaded CMC sheets promoted calcification and marker gene expressions, ALP activity for later phase of osteoblast differentiation as well as supported a new in vivo bone formation in a mouse calvaria defect model [70]. Hydroxyapatite/CMC hybrid hydrogel composites showed good adhesion, cell viability as well as osteogenic and odontogenic differentiation of dental pulp stem cells contrary to CMC hydrogel with poor cell adhesion [71]. There was no cytotoxicity. cell adhesion, proliferation and enhanced osteogenic activity of cells (alkaline phosphatase activity, expression of osteogenic marker genes and mineralization) were identified on the 4-layer 
poly(allylamine hydrochloride)/PAA films but the mechanical properties of films may play a critical role in modulating the behavior of osteoblasts [72]. The effects of PHYT on the activity of osteoblasts were evidenced by the enhanced production of osteopontin which regulates the growth of hydroxyapatite particles without any adverse influence on proliferation, ALP activity or collagen production. It was revealed that the micromolar amounts of PHYT added to the osteogenic medium significantly reduced mineralization without affecting cell viability, proliferation or collagen deposition by osteoblasts contrary to the insignificant effect of lower inositol phosphate [73]. This fact clearly supports our findings because more than $25 \%$ of phosphates in PHYT were released into the hardening liquid due to enzyme hydrolysis with phytase in CXI cements, thus, the majority of PHYT was present in the form of lower inositol phosphates even if the micromolar amount of inositols was desorbed from CXI surfaces neither could it affect on cell viability. In the above study, suppressing the proliferation of osteoblasts was observed in nonosteogenic medium with PHYT addition (micromolar) after long-term cultivation. CPC composed of TTCPM and 10\% PAA hardening liquid showed moderate osteoblast cytotoxicity after the first $24 \mathrm{~h}$ but the cytotoxicity decreased with culture time which was related to the possible release of unreacted PAA and lower $\mathrm{pH}$ value, thus the addition of a much higher concentration of PAA had a relatively weak effect on the long term cytotoxicity of cements [74]. Similar to CXI cements, the ALP activity of bone marrow stem cells rose after 14 days of culture as compared to 7 days as it was demonstrated in the case of hydroxyapatite cements with the lower addition of PAA (up to $2 \mathrm{wt} \%$ ) and no influence on the viability of cells was shown which confirms the insignificant effect of low PAA contents on in vitro cytotoxicity of CPC [75]. Note that the complex polyelectrolyte composition of hardening liquid was responsible for good bioactivity of noncytotoxic CXI cement extracts in relation to the production of calcium deposits, ALP activity and expression of osteogenic markers by osteoblasts.

\section{Conclusions}

The new enzymatically hardened hybrid tetracalcium phosphate/monetite cements with the small addition (up to $1 \mathrm{wt} \%$ ) of anionic PAA/CMC polyelectrolyte and hardening liquid containing PHYT/ phytase mixture were fully injectable and self-setting. The results showed the high resistance to wash-out in a short time after cement mixing with hardening liquid. The simple control of setting time (7-28 $\mathrm{min}$ ) was revealed via the change in $\mathrm{P} / \mathrm{L}$ ratio in cement paste or reaction time between PHYT and phytase. The larger differences in HAP particle morphologies with the change in $\mathrm{P} / \mathrm{L}$ ratio than in the content of PAA were identified in CXI cements where the higher fraction of needle-like and fine spherical HAP nanoparticles were found at $\mathrm{P} / \mathrm{L}$ ratio $=1.7$ and 2 respectively. The wet $C S^{\prime} s$ of CXI cements (up to $15 \mathrm{MPa}$ ) were comparable with cancellous bone. XRD analysis verified the fast transformation of cements to hydroxyapatite but the enhanced remains of origin calcium phosphates in hardened CXI cements were shown at higher P/L ratio and 1\%PAA content. The analysis of in vitro cytotoxicity confirmed the noncytotoxic character of cement extracts and the RT-qPCR osteogenic gene analysis demonstrated that the complex additives in CXI cements significantly supported the maturation and osteogenic activity of osteoblasts cultured in 50\% cement extracts.

Author Contributions: Conceptualization, L.M.; Investigation, L.M., M.G., R.Š., L.L.; Resources, T.S.; Writing-Original Draft Preparation, L.M., M.G.; Writing-Review \& Editing, L.M. All authors have read and agreed to the published version of the manuscript.

Funding: This work was supported by the Slovak Research and Development Agency under the contract No. APVV-17-0110.

Acknowledgments: This work was supported by the Slovak Research and Development Agency under the contract No. APVV-17-0110.

Conflicts of Interest: The authors declare no conflict of interest. The funders had no role in the design of the study; in the collection, analyses, or interpretation of data; in the writing of the manuscript, and in the decision to publish the results. 


\section{References}

1. Kolk, A.; Handschel, J.; Drescher, W.; Rothamel, D.; Kloss, K.; Blessmann, M.; Heiland, M.; Wolff, K.D.; Smeets, R. Current trends and future perspectives of bone substitute materials from space holders to innovative biomaterials. J. Cranio-Maxillofac. Surg. 2012, 40, 706-718. [CrossRef]

2. Baino, F.; Vitale-Brovarone, C. Bioceramics in ophthalmology. Acta Biomater. 2014, 10, 3372-3397. [CrossRef] [PubMed]

3. Yao, J.; Ho, A.M. Bone Graft Substitutes in the Treatment of Distal Radius and Upper Limb Injuries. Operative Tech. Orthop. 2009, 19,77-87. [CrossRef]

4. Lewis, G. Viscoelastic properties of injectable bone cements for orthopaedic applications: State-of-the-art review. J. Biomed. Mater. Res. Part B Appl. Biomater. 2011, 98B, 171-191. [CrossRef] [PubMed]

5. Mano, J.F.; Sousa, R.A.; Boesel, L.F.; Neves, N.M.; Reis, R.L. Bioinert, biodegradable and injectable polymeric matrix composites for hard tissue replacement: State of the art and recent developments. Comp. Sci. Technol. 2004, 64, 789-817. [CrossRef]

6. Ambrosio, L.; Guarino, V.; Sanginario, V.; Torricelli, P.; Fini, M.; Ginebra, M.P.; Planell, J.A.; Giardino, R. Injectable Calcium-Phosphate-Based Composites for Skeletal Bone Treatments. Biomed. Mater. 2012, 7, 024113. [CrossRef]

7. Zhang, J.; Liu, W.; Gauthier, O.; Sourice, S.; Pilet, P.; Rethore, G.; Khairoun, K.; Bouler, J.M.; Tancret, F.; Weiss, P. A Simple and Effective Approach to Prepare Injectable Macroporous Calcium Phosphate Cement for Bone Repair: Syringe-foaming Using a Viscous Hydrophilic Polymeric Solution. Acta Biomater. 2016, 31, 326-338. [CrossRef]

8. Kasuya, A.; Sobajima, S.; Kinoshita, M. In vivo degradation and new bone formation of calcium phosphate cement-gelatin powder composite related to macroporosity after in situ gelatin degradation. J. Orthop. Res. 2012, 30, 1103-1111. [CrossRef]

9. Thein-Han, W.; Liu, J.; Xu, H.K. Calcium phosphate cement with biofunctional agents and stem cell seeding for dental and craniofacial bone repair. Dent. Mater. 2012, 28, 1059-1070. [CrossRef] [PubMed]

10. Fernandez-Yague, M.A.; Abbah, S.A.; McNamara, L.; Zeugolis, D.I.; Pandit, A.; Biggs, M.J. Biomimetic approaches in bone tissue engineering: Integrating biological and physicomechanical strategies. Adv. Drug Deliv. Rev. 2015, 84, 1-29. [CrossRef] [PubMed]

11. Fellah, B.H.; Weiss, P.; Gauthier, O.; Rouillon, T.; Pilet, P.; Daculsi, G.; Layrolle, P. Bone repair using a new injectable self-crosslinkable bone substitute. J. Orthop. Res. 2006, 24, 628-635. [CrossRef] [PubMed]

12. Kovach, I.; Kosmella, S.; Prietzel, C.; Bagdahn, C.; Koetz, J. Nano-porous calcium phosphate balls. Colloids Surf. $B$ Biointerfaces 2015, 132, 246-252. [CrossRef] [PubMed]

13. Kruppke, B.; Farack, J.; Wagner, A.S.; Beckmann, S.; Heinemann, C.; Glenske, K.; Rößler, S.; Wiesmann, H.P.; Wenisch, S.; Hanke, T. Gelatine Modified Monetite as a Bone Substitute Material: An in Vitro Assessment of Bone Biocompatibility. Acta Biomater. 2016, 32, 275-285. [CrossRef] [PubMed]

14. Huang, Z.; Feng, Q.; Yub, B.; Li, S. Biomimetic properties of an injectable chitosan/nano-hydroxyapatite/ collagen composite. Mater. Sci. Eng. C 2011, 31, 683-687. [CrossRef]

15. Becherán-Marón, L.; Peniche, C.; Argüelles-Monal, W. Study of the interpolyelectrolyte reaction between chitosan and alginate: Influence of alginate composition and chitosan molecular weight. Int. J. Biol. Macrom. 2004, 34, 127-133. [CrossRef]

16. Volodko, A.V.; Davydova, V.N.; Glazunov, V.P.; Likhatskaya, G.M.; Yermak, I.M. Influence of structural features of carrageenan on the formation of polyelectrolyte complexes with chitosanInternational. J. Biol. Macromol. 2016, 84, 434-441. [CrossRef]

17. Sreeram, K.J.; Shrivastava, H.Y.; Nair, B.U. Studies on the nature of interaction of iron(III) with alginates. Biochim. Biophys. Acta 2004, 1670, 121-125. [CrossRef]

18. Sakamoto, A.; Qi, P.; Ohba, S.; Ohta, S.; Hara, Y.; Ogawa, T.; Tomokiyo, M.; Sasaki, A.; Takizawa, H.; Mochizuki, M.; et al. Bone regeneration by calcium phosphate-loaded carboxymethyl cellulose nonwoven sheets in canine femoral condyle defects. J. Biomed. Mater. Res. Part B 2019, 107B, 1516-1521. [CrossRef]

19. Grosfeld, E.C.; Hoekstra, J.W.M.; Herber, R.P.; Ulrich, D.J.O.; Jansen, J.A.; van den Beucken, J.J.P. Long-term biological performance of injectable and degradable calcium phosphate cement. Biomed. Mater. 2017, 12, 015009. [CrossRef] 
20. Kobayashi, H.; Fujishiro, T.; Belkoff, S.M.; Kobayashi, N.; Turner, A.S.; Seim, H.B.; Zitelli, J.; Hawkins, M.; Bauer, T.W. Long-term evaluation of a calcium phosphate bone cement with carboxymethyl cellulose in a vertebral defect model. J. Biomed. Mater. Res. 2009, 88A, 880-888. [CrossRef]

21. Chen, W.C.; Ju, C.P.; Wang, J.C.; Hung, C.C.; Lin, J.H.C. Brittle and ductile adjustable cement derived from calcium phosphate cement/polyacrylic acid composites. Dent. Mater. 2008, 24, 1616-1622. [CrossRef] [PubMed]

22. Graf, E.; Eaton, J.W. Antioxidant functions of phytic acid. Free Radic. Biol. Med. 1990, 8, 61-69. [CrossRef]

23. Fuster, J.M.B.; Cortes, S.P.; Bestard, J.P.; Freixedas, F. Plant phosphates, phytate and pathological calcifications in chronic kidney disease. Nefrologia 2017, 37, 20-28.

24. Szkudelski, T. Phytic acid-its influence on organism. J. Anim. Feed. Sci. 1997, 6, 427-438. [CrossRef]

25. Shibutani, T.; Heersche, J.N.M. Effect of medium $\mathrm{pH}$ on osteoclast activity and osteoclast formation in cultures of dispersed rabbit osteoclasts. J. Bone Miner. Res. 1993, 8, 331-336. [CrossRef] [PubMed]

26. Koutsoukos, P.G.; Amjad, Z.; Nancollas, G.H. The influence of phytate and phosphonate on the crystal growth of fluorapatite and hydroxyapatite. J. Colloid Int. Sci. 1981, 82, 599-605. [CrossRef]

27. Christel, T.; Christ, S.; Barralet, J.E.; Groll, J.; Gbureck, U. Chelate Bonding Mechanism in a Novel Magnesium Phosphate Bone Cement. J. Am. Ceram. Soc. 2015, 98, 694-697. [CrossRef]

28. Medvecky, L.; Stulajterova, R.; Giretova, M.; Sopcak, T.; Molcanova, Z.; Koval, K. Enzymatically hardened calcium phosphate biocement with phyticacid addition. J. Mater. Sci. Mater. Med. 2020, 31, 54. [CrossRef]

29. Wyss, M.; Pasamontes, L.; Friedlein, A.; Remy, R.; Tessier, M.; Kronenberger, A.; Middendorf, A.; Lehmann, M.; Schnoebelen, L.; Rothlisberger, U.; et al. Biophysical Characterization of Fungal Phytases (myo-Inositol Hexakisphosphate Phosphohydrolases): Molecular Size, Glycosylation Pattern, and Engineering of Proteolytic Resistance. Appl. Environ. Microbiol. 1999, 65, 359-366. [CrossRef]

30. March, J.G.; Grases, F.; Salvador, A. Hydrolysis of Phytic Acid by Microwave Treatment: Application to Phytic Acid Analysis in Pharmaceutical Preparations. Microchem. J. 1998, 59, 413-416. [CrossRef]

31. ISO. ISO Standard 1566 Dental Zinc Phosphate Cement; International Organization for Standardization: Geneva, Switzerland, 1978.

32. ISO. ISO 10993-12 Biological Evaluation of Medical Devices-Part 12: Sample Preparation and Reference Materials; International Organization for Standardization: Geneva, Switzerland, 2012.

33. ISO. ISO 10993-5 Biological Evaluation of Medical Devices-Part 5: Tests for In Vitro Cytotoxicity; International Organization for Standardization: Geneva, Switzerland, 2009.

34. Zor, T.; Selinger, Z. Linearization of the Bradford Protein Assay Increases Its Sensitivity: Theoretical and Experimental Studies. Anal. Biochem. 1996, 236, 302-308. [CrossRef] [PubMed]

35. Stephens, A.S.; Stephens, S.R.; Morrison, N.A. Internal control genes for quantitative RT-PCR expression analysis in mouse osteoblasts, osteoclasts and macrophages. BMC Res. Notes 2011, 4, 410. [CrossRef] [PubMed]

36. Sista, S.; Wen, C.; Hodgson, P.D.; Pande, G. Expression of cell adhesion and differentiation related genes in MC3T3 osteoblastsplated on titanium alloys: Role of surface properties. Mater. Sci. Eng. C 2013, 33, 1573-1582. [CrossRef] [PubMed]

37. Bohner, M. Calcium orthophosphates in medicine: From ceramics to calcium phosphate cements. Injury 2000, 31, 37-47. [CrossRef]

38. Krajewski, A.; Mazzocchi, M.; Buldini, P.L.; Ravaglioli, A.; Tinti, A.; Taddei, P.; Fagnano, C. Synthesis of carbonated hydroxyapatites: Efficiency of the substitution and critical evaluation of analytical methods. J. Mol. Struct. 2005, 744-747, 221-228. [CrossRef]

39. Apfelbaum, F.; Diab, H.; Mayer, L.; Featherstone, J.D.B. An FTIR study of carbonate in synthetic apatites. J. Inorg. Biochem. 1992, 45, 277-282. [CrossRef]

40. Wilson, R.M.; Elliott, J.C.; Dowker, S.E.P.; Rodriguez-Lorenzo, L.M. Rietveld refinements and spectroscopic studies of the structure of Ca-deficient apatite. Biomaterials 2005, 26, 1317-1327. [CrossRef] [PubMed]

41. Rey, C.; Collins, B.; Goehl, T.; Dickson, R.I.; Glimcher, M.J. The carbonate environment in bone mineral. A resolution enhanced Fourier transform infrared spectroscopy study. Calcif. Tissue Int. 1989, 45, 157-164. [CrossRef]

42. Moseke, C.; Gbureck, U. Tetracalcium phosphate: Synthesis, properties and biomedical applications. Acta Biomater. 2010, 6, 3815-3823. [CrossRef] 
43. He, Z.; Honeycutt, C.W.; Zhang, T.; Bertsch, P.M. Preparation and FT-IR Characterization of Metal Phytate Compounds. J. Environ. Qual. 2006, 35, 1319-1328. [CrossRef]

44. Saïed, N.; Aïder, M. Zeta Potential and Turbidimetry Analyzes for the Evaluation of Chitosan/Phytic Acid Complex Formation. J. Food Res. 2014, 3, 71-81. [CrossRef]

45. Nam, S.Y.; Lee, Y.M. Pervaporation and properties of chitosan-poly(acrylic acid) complex membranes. J. Membr. Sci. 1997, 135, 161-171. [CrossRef]

46. Salama, A.; Abou-Zeid, R.E.; El-Sakhawy, M. Calcium phosphate mineralization controlled by carboxymethyl cellulose-g-polymethacrylic acid. Soft Mater. 2016, 14, 154-161. [CrossRef]

47. Salama, A. Cellulose/calcium phosphate hybrids: New materials for biomedical and environmental applications. Int. J. Biol. Macromol. 2019, 127, 606-617. [CrossRef] [PubMed]

48. Ogiwara, T.; Katsumura, A.; Sugimura, K.; Teramoto, Y.; Nishio, Y. Calcium Phosphate Mineralization in Cellulose Derivative/Poly(acrylic acid) Composites Having a Chiral Nematic Mesomorphic Structure. Biomacromolecules 2015, 16, 3956-3963. [CrossRef]

49. Kamitakahara, M.; Kawashita, M.; Kokubo, T.; Nakamura, T. Effect of polyacrylic acid on the apatite formation of a bioactive ceramic in a simulated body fluid: Fundamental examination of the possibility of obtaining bioactive glass-ionomer cements for orthopaedic use. Biomaterials 2001, 22, 3191-3196. [CrossRef]

50. Cherng, A.; Takagi, S.; Chow, L.C. Effects of hydroxypropyl methylcellulose and other gelling agents on the handling properties of calcium phosphate cement. J. Biomed. Mater. Res. 1997, 35, 273-277. [CrossRef]

51. Bhowmik, R.; Katti, K.S.; Katti, D. Molecular dynamics simulation of hydroxyapatite polyacrylic acid interfaces. Polymer 2007, 48, 664-674. [CrossRef]

52. Yan, D.; Lou, Y.; Han, Y.; Wickramaratne, M.N.; Dai, H.; Wang, X. Controllable synthesis of poly(acrylic acid)-stabilized nanohydroxyapatite suspension by an ultrasound-assisted precipitation method. Mater. Lett. 2018, 227, 9-12. [CrossRef]

53. Kumar, A.P.; Mohaideen, K.K.; Alariqi, S.A.S.; Singh, R.P. Preparation and characterization of bioceramic nanocomposites based on hydroxyapatite (HA) and carboxymethyl cellulose (CMC). Macromol. Res. 2010, 18, 1160-1167. [CrossRef]

54. Garai, S.; Sinha, A. Biomimetic nanocomposites of carboxymethyl cellulose-hydroxyapatite: Novel three dimensional load bearing bone grafts. Colloids Surf. B Biointerfaces 2014, 115, 182-190. [CrossRef] [PubMed]

55. Guo, Y.; Ma, B.; Zhi, Z.; Tan, H.; Liu, M.; Jian, S.; Guo, Y. Effect of polyacrylic acid emulsion on fluidity of cement paste. Colloids Surf. A 2017, 535, 139-148. [CrossRef]

56. Majekodunmi, A.O.; Deb, S.; Nicolson, J.W. Effect of molecular weight and concentration of poly(acrylic acid) on the formation of a polymeric calcium phosphate cement. J. Mater. Sci. Mater. Med. 2003, 14, 747-752. [CrossRef] [PubMed]

57. Majekodunmi, A.O.; Deb, C.S. Poly(acrylic acid) modified calcium phosphate cements: The effect of the composition of the cement powder and of the molecular weight and concentration of the polymeric acid. J. Mater. Sci. Mater. Med. 2007, 18, 1883-1888. [CrossRef]

58. Jacquart, S.; Poquillon, D.; Dechambre, G.; Cazalbou, S.; Rey, C.; Combes, C. Mechanical properties of self-setting composites: Influence of the carboxymethylcellulose content and hydration state. J. Mater. Sci. 2016, 51, 4296-4305. [CrossRef]

59. Kucko, N.W.; Li, W.; García Martinez, M.A.; Rehman, I.; Ulset, A.S.T.; Christensen, B.E.; Leeuwenburgh, S.C.G.; Herber, R.P. Sterilization effects on the handling and degradation properties of calcium phosphate cements containing poly (D,L-lactic-co-glycolic acid) porogens and carboxymethyl cellulose. J. Biomed. Mater. Res. B Part B Appl. Biomater. 2016, 107B, 2216-2228. [CrossRef]

60. Alves, H.L.; dos Santos, L.A.; Bergmann, C.P. Injectability evaluation of tricalcium phosphate bone cement. J. Mater. Sci. Mater. Med. 2008, 19, 2241-2246. [CrossRef]

61. Dos Santos, L.A.; De Oliveira, L.C.; Rigo, E.C.S.; Carrodeguas, R.G.; Boschi, A.O.; De Arruda, A.C.F. Influence of Polymeric Additives on the Mechanical Properties of a-Tricalcium Phosphate Cement. Bone 1999, 25, 99S-102S. [CrossRef]

62. Hurle, K.; Weichhold, J.; Brueckner, M.; Gbureck, U.; Brueckner, T.; Goetz-Neunhoeffer, F. Hydration mechanism of a calcium phosphate cement modified with phytic acid. Acta Biomater. 2018, 80, 378-389. [CrossRef] 
63. Horiguchi, Y.; Yoshikawa, A.; Oribe, K.; Aizawa, M. Fabrication of chelate-setting hydroxyapatite cements from four kinds of commercially-available powder with various shape and crystallinity and their mechanical property. J. Ceram. Soc. Jpn. 2008, 116, 50-55. [CrossRef]

64. Baylink, D.J.; Finkelman, R.D.; Mohan, S. Growth factors to stimulate bone formation. J. Bone Miner. Res. 1993, 8, S565-S572. [CrossRef] [PubMed]

65. McCarthy, T.L.; Centrella, M.; Canalis, E. Regulatory effects of insulinlike growth factors I and II on bone collagen synthesis in rat calvarial cultures. Endocrinology 1989, 124, 301-309. [CrossRef] [PubMed]

66. Zhao, W.; Wang, Z.; Xu, A.; Sahai, N. Osteocalcin facilitates calcium phosphate ion complex growth as revealed by free energy calculation. Phys. Chem. Chem. Phys. 2018, 20, 13047-13056. [CrossRef] [PubMed]

67. Flade, K.; Lau, C.; Mertig, M.; Pompe, W. Osteocalcin-Controlled Dissolution-Reprecipitation of Calcium Phosphate under Biomimetic Conditions. Chem. Mater. 2001, 13, 3596-3602. [CrossRef]

68. Gericke, A.; Qin, C.; Spevak, L.; Fujimoto, Y.; Butler, W.T.; Srrrensen, E.S.; Boskey, A.L. Importance of Phosphorylation for Osteopontin Regulation of Biomineralization. Calcif. Tissue Int. 2005, 77, 45-54. [CrossRef] [PubMed]

69. Kartsogiannis, V.; Ng, K.W. Cell lines and primary cell cultures in the study of bone cell biology. Mol. Cell. Endocrinol. 2004, 228, 79-102. [CrossRef] [PubMed]

70. Qia, P.; Ohba, S.; Hara, Y.; Fuke, M.; Ogawa, T.; Ohta, S.; Ito, T. Fabrication of calcium phosphate-loaded carboxymethyl cellulose nonwoven sheets for bone regeneration. Carbohydr. Polym. 2018, 189, 322-330. [CrossRef] [PubMed]

71. Teti, G.; Salvatore, V.; Focaroli, S.; Durante, S.; Mazzotti, A.; Dicarlo, M.; Mattioli-Belmonte, M.; Orsini, G. In vitro osteogenic and odontogenic differentiation of human dental pulp stem cells seeded on carboxymethyl cellulose-hydroxyapatite hybrid hydrogel. Front. Physiol. 2015, 6, 297. [CrossRef]

72. Chien, H.W.; Tan, S.F.; Wei, K.L.; Tsai, W.B. Modulation of the functions of osteoblast-like cells on poly(allylamine hydrochloride) and poly(acrylic acid) multilayer films. Colloids Surf. B Biointerfaces 2011, 88, 297-303. [CrossRef] [PubMed]

73. Addison, W.N.; McKee, M.D. Inositol hexakisphosphate inhibits mineralization of MC3T3-E1 osteoblast cultures. Bone 2010, 46, 1100-1107. [CrossRef] [PubMed]

74. Khashaba, R.M.; Moussa, M.M.; Mettenburg, D.J.; Rueggeberg, F.A.; Chutkan, N.B.; Borke, J.L. Polymeric-Calcium Phosphate Cement Composites-MaterialProperties: In Vitro and In Vivo Investigations. Int. J. Biomater. 2010, 691452. [CrossRef]

75. Li, X.; He, F.; Ye, I. Preparation, characterization and in vitro cell performance of anti wash-out calcium phosphateement modified by sodium polyacrylate. RSC Adv. 2017, 7, 32842. [CrossRef] 